\title{
Novel method of healing the fibre reinforced thermoplastic composite: a potential model for offshore applications.
}

\author{
GUPTA, R., HUO, D., WHITE, M., JHA, V., STENNING, G.B.G., \\ PANCHOLI, $\mathrm{K}$.
}




\title{
Novel Method of Healing the Fibre Reinforced Thermoplastic Composite: A Potential Model for Offshore Applications
}

\author{
Ranjeetkumar Gupta ${ }^{1}$, Dehong $\mathrm{Huo}^{2}$, Maggie White ${ }^{3}$, Vineet Jha ${ }^{4}$, Gavin B. G. Stenning ${ }^{5}$, Ketan \\ Pancholi $^{1 *}$
}

${ }^{1}$ School of Engineering, Robert Gordon University, Aberdeen AB10 7GE, UK

${ }^{2}$ School of Engineering, Newcastle University, Newcastle upon Tyne, NE1 7RU, UK.

${ }^{3}$ School of Chemical Engineering \& Advanced Materials, Newcastle University, NE1 7RU, UK.

${ }^{4}$ GE Oil \& Gas, Newcastle upon Tyne, NE6 3PF, UK.

${ }^{5}$ ISIS Neutron and Muon Facility, STFC Rutherford Appleton Laboratory, Didcot OX11 0QX, UK

*Correspondence: k.pancholi2@rgu.ac.uk; Tel.: +44-1224-262317.

\begin{abstract}
:
Continuous fibre reinforced thermoplastic composites are increasingly finding their use as engineering materials in many industries due to the excellent fire, smoke and toxicity performance. However, the composite component produced using automated continuous fibre reinforced thermoplastic tapes laying machine are susceptible to sudden failure emanating from microscale cracks. This study demonstrates the healing potential of a layered Glass Fibre Reinforced Polymer (GFRP) composite consisting of alternative layers of GFRP and a magnetic polyamide-6 (PA-6) nanocomposite (PNC) film. The self-healing process is presented in three steps, viz. (i) polymer nanocomposite synthesis, (ii) preparation of the layered GFRP layered composite sample and (iii) selfhealing and testing of GFRP layered composite sample. Firstly, the multilayer dog bone sample consisting of a magnetic polymer nanocomposite (PNC) film sandwiched between thermoplastic unidirectional GFRP tapes are prepared. Healing is triggered by exposing the damaged multilayer sample to microwave causing selective heating of nanocomposite film and its subsequent melting. The healing process completes when liquid polymer fills the micro-crack in the multilayer tape through capillary action and solidifies upon cooling. The healing yields $84 \%$ of the undamaged tensile strength recovery. Results demonstrate the potential application of an autonomous self-healing method for thermoplastic composite used in the offshore environment.
\end{abstract}

\section{INTRODUCTION}

Fibre-reinforced polymer (FRP) composites are finding extensive use in the offshore industry. The products such as composite modules, spoolable pipes and pressure vessels are now manufactured using FRP for light-weighting and better management of the stress and strains resulting from the environmental loads. The most viable and demanding applications of glass-fibre reinforced plastics are enlisted in Figure 1. Recently, a challenge of accessing deep-water fields and other places has led to development of hybrid flexible riser consisting of metallic and thermoplastic composite layers. The composite section of the flexible or spoolable pipe also uses either carbon or glass fibre thermoplastic tapes, as they provide high damage and impact tolerance as well as chemical and solvent resistance combined with unlimited shelf life, low storage costs, weldability and recyclability (1-3). However, the major benefit of using thermoplastic is that it does not require an autoclave for manufacturing a large component. Majority of components used in offshore industry are very large and it is difficult to process them in an autoclave. With the methods such as automated tape placement, the kilometre-long quality composite pipes with well-consolidated layers are manufactured. Moreover, the cost and processing time is also very less. 
Enhancing the access of offshore industries including renewables to the high technology composites requires reduction in cost through increase in reliability, dependable life and material performance. A small increase in reliability of the composite materials results into higher productivity of many offshore operations such as a typical subsea tie-back projects (4). Often these GRFP products are susceptible to scratches, cracks, and punctures, which can result in dangerous spillages, safety hazards, or simply loss of productivity. Although the strength and stiffness of anisotropic composite materials can be attuned accurately to withstand the expected loads, this may result in a structure less tolerant to damage in certain areas (5). As seen in computed tomography images in Figure 2 (a) and (b) (6), the layered thermoplastic composites structure can develop safety critical defects at considerably lower load. Furthermore, this early onset of the defects initiates the development of large transverse cracks until the entire component fails. Many other failure modes for composites in safety critical applications exist and can cause sudden failures, however, it all starts with micro-cracking of the composite matrix.

Since microscale failure such as cracks occurs at an early stage of operation $(7,8)$ it is crucial to identify and repair critical micrometre scale defects early on (9-11). However, it is difficult to detect micron size delamination and therefore, if autonomous material healing is carried out at regular interval, the damage tolerance and productivity of the material can be improved significantly, and it will result in increased reliability by avoiding sudden catastrophic structural failures.

Many methods of self-healing of composites through application of heat and damage have been reported. Most methods are related to healing the epoxy based composite materials where liquid healing agents are incorporated into the structure using various methods (12-15). For example, a hollow fibre containing liquid healing agent can be 3D weaved into composite prepeg for mimicking veins in human body. Hollow fibre composite with 1 to $3 \%$ $\mathrm{v} / \mathrm{v}$ fraction showed capability to arrest the crack propagation (16). In other self-healing strategy, the thermoplastic resin is combined with epoxy to heal the cracks in thermoset matrix composite through repetitive melting of thermoplastic (17). When hybrid polymer matrix in composites is heated, the thermoplastic filled the crack in epoxy. Many methods for healing the nanocomposite or polymer alone, however, not related to a topic under discussion, are also mention worthy. These methods use reversible bond in polymer and magnetic stimuli to recover the bonding strength of the polymer. Initial strength of such material is still limited for the structural application (18).

This work proposes a self-healing system for structural applications which can be operated remotely and integrated with sensing. As a part of this work, the basic component of such system, the self-healing multilayer tape consisting of a low melting temperature nanocomposite film sandwiched between high melting point thermoplastic unidirectional fibre-reinforced prepreg or tape was prepared. The component made using these tapes can be exposed regularly to external stimuli to melt the PNC film and encourage liquid polymer to fill the microcracks through capillary action. The infiltration of viscous polymer in to the microcrack arrests the stress intensity at the tip which enhances fracture toughness by forming wedge shape film capable of holding crack opening under maximum loading cycle condition. This process holds back the crack propagation for significant time (19). Choice of stimuli can be magnetic field or microwave that can be applied remotely to FRP component. Together with crack-gap closing mechanism, the microwave source can be interfaced with electronic triggering 
mechanism to affect the self-healing in remotely located FRP components $(17,20)$. Moreover, the healing can also be performed multiple times by applying micro-wave or magnetic stimuli $(21,22)$.

In order to achieve efficient microwave induced melting of the polymer matrix in NC, the uniform dispersion of magnetic nanoparticles (MNP) in polymer matrix is essential for such application. Increasing MNP loading reduces the inter-particle distances allowing formation of the agglomerates due to short range Van der Waals or hydrogen bonds. As in at air-liquid interface in bubbles, the particles tend to agglomerate at phase interfaces such as solid-solid, solid-liquid or air-liquid $(23,24)$. Presence of MNP agglomerates in polymer matrix cause an uneven response to the applied stimulus; as the agglomerated particles region will absorb more stimulus energy and will melt the polymer excessively or undergo pyrolysis (21). Additionally, the dispersion also affects the size of crystal and degree of crystallinity of the polymer matrix in PNC. Low degree of crystallinity increases the melting temperature of PNC and the crystallite size affects the mechanical properties of the PNC. The dispersion also affects the magnetic properties of the PNC. In order to maintain lower melting temperature and better mechanical properties as well as to avoid pyrolysis, the PNC preparation should be optimized to control the particle dispersion. Here, the hydrophobic oleic acid (OA) coating is applied on the iron oxide MNPs for better dispersion and therefore, optimizing all the properties including magnetic property of PNC (25). The OA loading (w/w \%) on the iron oxide MNPs is varied to determine the most suitable weight fraction for better dispersion of MNPs in PNC. The results related to dispersion, magnetic properties, degree of crystallinity and crystallite size are included to show the optimization of PNC.

This work reports the stimuli induced healing potential of the layered thermoplastic composite containing PNC film as healing agent (Figure 3). Firstly, the magnetic PA-6 polymer nanocomposite was synthesised by uniformly dispersing iron (III) oxide MNPs in polymer matrix. The in-situ ring opening polymerisation method was used for uniform dispersion of MNPs in PA-6 matrix. Subsequently, the PNC film of 0.2 mm was prepared for incorporation into layers of GFRP composite, as seen in Figure. 4 and Supplementary Data S1. The standard (26) GFRP dog bone composite samples were developed by sandwiching two PNC films between three layers of GFRP tapes. Secondly, the dog bone samples with and without damage, were tested to determine tensile strength before and after healing.

\section{MATERIALS AND METHODS}

The steps involved in preparing PNC, multilayered glass fibre tape and characterisation/testing methods are mentioned in this section. However, the detailed characterization methods and analysis of their data are included in the Supplementary section S3.

\subsection{Materials}

ع-caprolactam (CL) (99\% purity), 3.0 M Ethyl Magnesium Bromide (EtMgBr) solution in diethyl ether, NAcetyl Caprolactam (NACL) (99\% purity), Iron(III) oxide MNPs ( $<50 \mathrm{~nm}$ particle size) and oleic acid (OA) (99\% purity) were purchased from Sigma-Aldrich Company Ltd. Dorset, UK; and used as received. Deionized water with $18 \mathrm{MO}$ conductivity was used throughout the experiment. Glass fibre tape (PA6) with $0.18 \mathrm{~mm}$ thickness 
was purchased from Vitcas, and the synthesized polymer nanocomposite was used for composite sample preparation.

\subsection{Experimental methods}

i. Optimisation of synthesis of PA-6 magnetic polymer nanocomposite.

Since dispersion of MNPs in polymer determines the magnetic property, melting temperature (degree of crystallinity), mechanical properties (crystallite size) and pyrolysis of PNC, the hydrophobic oleic acid coated Iron Oxide MNPs were used in preparation of PNC. Variation in hydrophobic coating density on MNPs' surface affects the dispersion, and to optimize the hydrophobic coating density on surfaces of iron oxide MNPs, the OA loading was varied from $22 \mathrm{w} / \mathrm{w} \%$ to $55 \mathrm{w} / \mathrm{w} \%$. Furthermore, the MNPs with different OA loading were used for in-situ polymerization of PNC. Unlike a melt blending method, where MNPs are dispersed in viscous polymer melt using shear force, the in-situ method allows uniform dispersion of MNPs in the low viscosity monomer.

A batch of PNC was prepared by mixing $1 \mathrm{w} / \mathrm{w} \%$ MNPs in $30 \mathrm{~g}$ melted CL. The resulting mixture was sonicated for 30 minutes to disperse MNPs. For ring opening polymerisation, the catalyst EtMgBr and activator NACL was introduced to the mixture kept at $150^{\circ} \mathrm{C}(423.15 \mathrm{~K})$. As soon as NACL was introduced, the mixture was instantly polymerized. Once the nanocomposite was cool, then boiling water was used to wash recover nanocomposite from the glassware. The nanocomposite was then thoroughly washed before further characterization. Total six compositions (Sample A to Sample F), as seen in Table 1, were prepared for optimization. Detailed MNP coating and PNC preparation methods are included in Supplementary Data S2.

\section{ii. Characterisation of the synthesised PNC}

All six compositions containing $1 \mathrm{w} / \mathrm{w} \%$ MNPs coated with different OA loading $(22,33,44$ and $55 \mathrm{w} / \mathrm{w}$ $\%$ ) were characterised using ATR-FTIR (Attenuated Total Reflection- Fourier Transmission Infrared Spectroscope) to determine its chemical composition and confirm the successful polymerization of CL forming PA6 polymer. The IR spectra is not used for calculating the degree of crystallinity. Previous studies have shown that the dispersion state of MNPs in the polymer modifies the crystallite size and degree of crystallinity. To determine effect on degree of crystallinity and crystallite size, all compositions containing MNPs with variable OA loading were characterized using Differential Scanning Calorimetry (DSC) and X-ray Diffraction (XRD).

It is unlikely that increasing OA loading of the iron oxide nanoparticle coating would result in better dispersion. For optimizing properties of PNC would require knowledge of correlation of dispersion state with the variety of properties including magnetic property. To establish correlation, the dispersion sate was calculated from the Transmission Electron Microscopy (TEM) and Small \& Wide-angle X-ray scattering (SAXS/WAXS) results. An average particulate agglomeration size over a large surface area of PNC was calculated from SAXS/WAXS data through implementation of the Guinier and Porod law. Calculated average size then compared with the TEM results for validation. Furthermore, the magnetic saturation properties at temperatures of $100 \mathrm{~K}$ and $400 \mathrm{~K}$ were measured using Quantum Design MPMS 3, integrated with Superconducting Quantum Interference Device (SQUID) detection system and correlated with coating/dispersion state. All characterisation methods are described in detail in Supplementary Data S3. 


\section{iii. Preparation and self-healing of GFRP composite sample.}

The virgin samples were prepared using three glass fibre tapes placed together with PNC film in between. The cracked-virgin sample was made by creating the crack in the middle narrow section of the dog-gone sample. A through crack of $2 \mathrm{~mm}$ length was created as a central snip on the middle of the narrow section of the dogbone using sharp Stanley knife. The crack created perpendicular to the tensile load direction and it was $2 \mathrm{~mm}$ away from the outermost edge of the dog-bone. The dog-bone sample with all dimensions are included as Figure 1 in the Supplementary data, section S1. The glass fibre tape was cleaned using mild acidic solution and ultrasound radiation to make its surface contaminant free allowing its enhanced bonding to PNC. The tape placement was done using hot gun (rating $50 \mathrm{KW}$ ) as a means of melting the PNC and setting it between the clean glass fibre tapes. All the samples were made to the size of standard 'dog-bone' specimen for composite testing, as mentioned in Figure 4.

The composite GFRP tapes were self-healed at $2.45 \mathrm{GHz}$ for 30 seconds at $900 \mathrm{~W}$ after successive crack propagation by microwave induction stimuli using Microwave oven. After $30 \mathrm{~s}$, the PNC film between GFRP tapes was melted at the crack location and the liquid PNC fills the crack. After cooling at room temperature for 30 minutes, the samples were tensile tested. The sample was not mechanically compressed after healing.

\section{iv. Mechanical testing of Self-Healed Composite Samples}

Tensile testing was carried out using Instron 1195 tensile testing machine according to ASTM D638, with a full-scale load cell range set to $50 \mathrm{kN}$. The crack on the specimen was created such that the applied tensile load direction was perpendicular to crack. It represented most onerous scenario. The standard 'dog-bone' specimen was used for measuring the desired stress-strain response. The crosshead displacement rate was set to vary at a rate of $0.5 \mathrm{~mm} / \mathrm{min}$. The stopping criteria for the test was fixed at $50 \%$ change in the maximum load capacity, and allowable length extension of $20 \mathrm{~mm}$ and change of width up to $3 \mathrm{~mm}$.

\section{RESULTS AND Discussions}

Proposed self-healing method depends on melting of PNC film to fill the micro-cracks in thermoplastic unidirectional glass fibre tape composite. Suitability of PNC for self-healing composite was determined by its ability to melt at low temperature without pyrolysis, ability to provide strength to repaired section and similarity in chemical structure with original material. As dissimilar polymers are difficult to bond with each other, the PA6 polymer, same as GFRP tape, was chosen to prepare PNC. For ensuring low melting temperature and mechanical strength of repair, high degree of crystallinity and small crystallite size was maintained while preparing the material. The magnetic property of the PNC was also optimized for maximum heating in response to external microwave field. Characterisation of the PNC for achieving optimized properties is described below.

\subsection{Chemical composition of PA6 nanocomposite.}

FTIR peaks confirmed successful synthesis of polyamide 6 (PA6), matching with template standard chemical groups associated with commercial grade PA6 (27). As seen in Figure 5, the absorbance band corresponding to N-H stretching and hydrogen bonding as found in the PA6 was observed at $3296 \mathrm{~cm}^{-1}$. Prominent peaks related to methylene $\left(\mathrm{CH}_{2}\right)$ asymmetric and symmetric stretching vibrations absorbance band 
related to PA6 were also observed at $2935 \mathrm{~cm}^{-1}$ and $2861 \mathrm{~cm}^{-1}$ confirming formation of PA6 (27)(28). In addition, these results also confirmed the presence of the amide II band of primary amides, which occurred due to stretching vibration of the $\mathrm{C}=\mathrm{O}$ double bond and further ascribed to the functionality of the amide $\mathrm{I}$ band. Peaks were also seen around $1540 \mathrm{~cm}^{-1}$ and $1633 \mathrm{~cm}^{-1}$, which were additional peaks relating to the previously mentioned amide I and II bands of the primary type but also the vibration due to stretching of the $\mathrm{C}-\mathrm{N}$ bond, which then resulted in a vibration due to bending of the N-H bond and the CO-NH bend (29).

As seen in Figure 5, the levels of crystallinity was seen decreasing with increase in OA concentration in coating, which was confirmed by observation of shift in the peaks from $1538 \mathrm{~cm}^{-1}$ to $1539 \mathrm{~cm}^{-1}, 1537 \mathrm{~cm}^{-1}, 1537$ $\mathrm{cm}^{-1}$, to $1531 \mathrm{~cm}^{-1}$ for increasing proportion of OA coating (28). The degree of crystallinity is determined from the position and intensity of these crystalline bands, as well as the broader bands from the amorphous phase (30). It is inferred that the degree of crystallinity is moderately high in the polymer samples with low concentration of $\mathrm{OA}$, as the amide II band, sensitive to the crystalline structure, appeared around $1540 \mathrm{~cm}^{-1}$ in spectrum of Sample $C$. Presence of the carboxylic end group at the end of OA fatty acid chain has interacted with $\mathrm{NH}_{2}$ of the polyamide chain and reduced polymer chain mobility causing slow formation of crystals and therefore, higher degree of crystallinity (31). The wavelength fingerprint for OA is typically around $1700 \mathrm{~cm}^{-1}$, however, the most closest absorbance band was observed at $1716-1718 \mathrm{~cm}^{-1}$ (32). Detailed list of matching peaks is listed in Supplementary Data S4.

Degree of crystallinity in PNC affects the melting temperature. According to FTIR results, the PNC with lowest proportion of OA, i.e. Sample $C$ has highest degree of crystallinity and hence, low melting temperature. It is, therefore, the Sample $C$ was found best for application.

\subsection{Effect of OA loading on dispersion of nanoparticles.}

Dispersion of MNPs are important to achieve desired properties of the PNC. A good dispersion with small agglomeration diameter in PNC ensures high degree of crystallinity, small crystallite size and uniform magnetic saturation. To achieve better dispersion of the MNPs, OA concentration in coating was varied. TEM images were obtained to quantify the dispersion state of the MNPs. The TEM images of microtome nanocomposite slices show that the dispersion of particles improves with coating. Although Sample E and Sample $F$ were seen promoting agglomeration due to excessive amount of OA. At lower concertation, OA coating promotes the dispersion of MNPs in the polymer matrix of PA6 as it imparts hydrophobic properties to MNPs (33). When hydrophobic properties of polymer and MNPs are similar, a homogenous dispersion can be achieved. As seen in Figure 6, the increased concentration of OA in the MNP coating formed the agglomeration due high OA adsorption. Homogenous dispersion is responsible for smallest crystallite size and degree of crystallinity in Sample $C$, which is also confirmed by the XRD results later.

TEM only provides the information on dispersion state of MNPs at point scale. However, SAXS can determine dispersion state on broader scale (area) than TEM. In order to determine the dispersion, the PNC was characterized using SAXS/WAXS technique.

The filler structure and their dispersivity amongst the confirmations of polymer chains inside a PNC is widely studied with scattering techniques. Measurement of hard particle dispersivity in the soft polymer using a small angle scattering is based on the variation of the X-ray scattering length density across the sample. The scattering density depicted by the scattering intensity $\mathrm{I}(\mathrm{q})$ is sensitive to density variation and hence, allows determination 
of statistics of hard particle dispersion. The small angle ensures absence of scattering due to sample surface roughness (34). This helps in identifying numerical values of the MNPs radius of gyration and complex agglomerates (35).

Figure 7 represents the scattering intensity I(q), plotted as a function of the scattering vector "q" for all the samples studied herein. The SAXS profile shows two regions, the one which is flat is due to the polymer response, as is very clear from the Pristine PA6 data plot alone; second is the very high slope curve pertaining to the response of the nanoparticles in the samples. Absence of diffraction peaks at lower OA concentration confirms good dispersion and low interaction between MNPs.

The cumulatively slope-dropping region is a characteristic of Porod scattering response from the MNPs (36). And the Guinier region precedes the Porod region, wherein the scattering of this region reflects the radius of gyration of the MNPs a per the Guinier's law. By calculating the radius of gyration, the average diameter of MNPs in a volume of PNC were calculated and summarised in the table below. Detailed analysis method of SAXS data is discussed in Supplementary Data S5.

The average diameter of MNPs calculated with the SAXS data are listed in Table 2 and their values lie in proximity of that obtained with TEM above. This confirms that the Sample $C$ has the lowest average diameter of MNPs and also has the least agglomerates. Further, the WAXS curves for nanocomposites shows that some of the peaks associated to the crystalline lattices of PA6 become sharper for Sample $C$ and peak height decreases for samples with higher OA concentration in comparison to Sample A. The increase of intensity of peaks corresponding to PA6 reflection planes of (010) and (012) for these nanocomposites was observed. Based on these high OA loaded samples, it can be concluded that the large crystals in PNC can be formed with a presence of thick lamellae produced by excessive OA concentration in coating (33). Again, Sample C emerges as a favourable choice for self-healing application as aggregates of MNPs can induce local heating and subsequently, pyrolysis when they interact with electromagnetic wave such as microwave.

\subsection{Effect of MNPs dispersion on degree of crystallinity and crystallite size.}

The DSC results for all the samples, as seen in Figure 8, exhibit the noticeable melting endothermic peaks and clearly depicting the glass transition temperature of all polymer samples. The results of the thermal analysis represent the glass transition temperature $\left(\mathrm{T}_{\mathrm{g}}\right)$ occurrence of the pristine polymer at around $46^{\circ} \mathrm{C}$ that matches approximately the previously reported values (37). The melting temperature $\left(\mathrm{T}_{\mathrm{m}}\right)$ observed in DSC results were found to be slightly lower than the published values, at around $220{ }^{\circ} \mathrm{C}$ (493.15 K) (37). Additionally, as seen in Supplementary Data S6, the melting temperature of the nanocomposite was found to be increasing with the increase in $\mathrm{OA}$ concentration of the coating. However, the $\mathrm{T}_{\mathrm{g}}$ also showed linear relation with OA concentration, which is result of decrease in degree of crystallinity. Decrease in degree of crystallinity in high OA concentrations PNC was responsible for increases in the melting temperature.

The DSC results also show that the wetting of the MNPs by the polymer melt was increased as a result of OA coating on MNPs. The fatty acid chain in OA coating rendered hydrophobicity to the surface of MNPs and promoted wetting by the hydrophobic polymer at interface. With increased OA concentration, the denser fatty acid chain on surface of MNPs promoted strong attractive interaction with surrounding polymer chain, leading to reductions in cooperative segmental mobility in the polymer and an increase in $T_{g}(38-40)$. Though the decrease in the degree of crystallinity observed with the increased OA concentration can be attributed to the MNPs 
inclusion which restricts the movement and limit the growth of PA6 crystals, but the excessive OA assisted formation of agglomeration in the Sample $F$ showed lowest degree of crystallinity, even lower than the Sample $B$ containing uncoated MNPs. Such decrease in degree of crystallinity due to agglomerates was also observed in previously reported works when increase in the wt\% of nano-inclusions was responsible for formation of agglomerates (41).

Furthermore, the results on degree of crystallinity of PNC were confirmed by the XRD results. As seen in Figure 9, the main characteristic peaks were obtained by the XRD matches with the (hkl) values of (220), (311), (400), (511) and (440). These were then matched with the JCPDS file number 82-1533, which corresponded to $\mathrm{Fe}_{3} \mathrm{O}_{4}$ phase. The crystallite sizes of MNPs were calculated from FWHM of the most intense peaks using the Debye-Scherer formula as listed in Supplementary Data S7. The matrix crystallization behavior significantly influences the mechanical and physical properties of the designed nanocomposites. The pristine PA6 shows a sharp crystallization peak as compared with that of the nanocomposite samples. The broader peaks resulting due to the MNP inclusions, as shown by the nanocomposite samples are hinting towards non-uniform crystal phases.

The two broad crystalline peaks associated with crystalline to amorphous ratio, decreased for Sample C showing increase in crystallinity as compared to pristine and uncoated sample and further with increase in OA loading there is gradual amorphous sites development. Also, as observed in Figure 9 the increased OA loading suppressed the intense $\mathrm{Fe}_{3} \mathrm{O}_{4}$ peaks in Sample $F$, showing maximum broadening and minimum intensity.

Furthermore, the reduction in crystal size justifies the enhanced mechanical response as observed in similar study (42). These can help conclude, bare MNPs tend to agglomerate upon drying due to strong magnetic dipoledipole interaction and therefore, they appear as agglomerates. Once coating was applied, the non-magnetic hydrophobic oleic acid layer formed on the surface of each particles that prevented or partially hindered magnetic interaction and hence, the mean crystallite size or agglomerates reduced as highlighted in Supplementary Data S7; especially the Sample $C$ showed the least crystallite/agglomerate size.

\subsection{Effect of dispersion on magnetic properties.}

The magnetic properties of the synthesised samples were assessed by magnetization curves at $100 \mathrm{~K}$ and $400 \mathrm{~K}$ temperatures. The hysteresis loops of all PNC samples were found to be similar as paramagnetic material. However, the variation in the magnetic properties due to dispersion state of MNPs resulting from the variation in OA loading is clearly distinguishable in Figure 10 (a) and (b). On application of homogeneous magnetic field of 50000 Oe, (full scale plots included in Supplementary Data S8) the PNC shows a magnetic moment ratio $\left(\mathrm{M}_{\mathrm{r}} / \mathrm{M}_{\mathrm{s}}\right)$ of remanence magnetisation $\left(\mathrm{M}_{\mathrm{r}}\right)$ to saturation $\left(\mathrm{M}_{\mathrm{s}}\right)$ of $0 \%$ and $47 \%$ for Sample A and Sample B respectively. The ratio values were found to be $39 \%, 33 \%, 48 \%$ and $27 \%$ for Sample C-F respectively at $100 \mathrm{~K}$. After increasing temperature to $400 \mathrm{~K}$, the values for $\mathrm{M}_{\mathrm{r}} / \mathrm{M}_{\mathrm{s}}$ ratio were seen to be reduced (except for Sample A) to $32 \%$ for Sample B, and $29 \%, 24 \%, 33 \%$ and $21 \%$ for Sample $C-F$ respectively. Though the highest value observed for Sample E (even higher than uncoated MNPs PNC) is clearly distinctive indication of the uneven dispersion and agglomeration observed at higher OA loading, as observed in TEM and SAXS results. The $\mathrm{M}_{\mathrm{r}} / \mathrm{M}_{\mathrm{S}}$ ratio for the Sample F coating was found to be lowest amongst all PNCs which could be attributed to thicker coating owing to higher OA loading, as seen in similar studies $(43,44)$. Despite of agglomeration was found in Sample $F$, the organic material (OA) created a thick enough interphase between polymer matrix and MNP agglomerates to cause a reduction in overall magnetic properties. The observance of the larger coercive force in 
the hysteresis loop at lower temperature $(100 \mathrm{~K})$ as compared to that at higher temperature ( $400 \mathrm{~K})$ confirms the paramagnetic behavior of the designed PNCs (45). The hysteresis loops of all the synthesised PNCs revealed symmetric behavior similar to that of ferromagnetic materials (46), confirming suitability of the synthesised PNCs for magnetic applications (21), especially for stimuli-based self-healing. Independent of the MNPs weight percentage in PNCs, the coercivity of all PNC samples (except pristine sample that showed zero magnetisation) took a value between 270-310 Oe and 110-120 Oe at temperatures of $100 \mathrm{~K}$ and $400 \mathrm{~K}$ respectively. Here, the hysteresis loop shows small coercive force with increase in OA loadings on MNPs suggesting transition from hard to soft magnetic behavior of the PNCs. In summary, the values of saturation and remanence magnetisation of PNCs as seen in Figure 10 (a) and (b) were found to be inversely proportional to the amount of OA loading in the MNP coating, with an exception of Sample E. Even though Sample E showed highest $\mathrm{M}_{\mathrm{r}} / \mathrm{M}_{\mathrm{s}}$ ratio, Sample $C$ was chosen because of its best dispersion of MNPs, which will prevent localized pyrolysis of the PNC during stimuli-based self-healing.

\subsection{Selection of the suitable PNC for composite sample preparation.}

The onset of crystallization temperature steadily increases with the increase in OA content, indicating that the MNPs are acting as heterogenous nucleation agents in PA6 matrix and hence the higher crystallization rate than the pristine PA6. Moreover, the decreased melting peak can attribute to the decreased crystal size observed in XRD $(47,48)$. The DSC and XRD results confirmed that Sample $C$ showed highest degree of crystallinity and smallest crystallite size, respectively. As discussed in section 3.3, the DSC and XRD results imply that Sample $C$ will have highest tensile strength and lowest melting temperature. Additionally, the magnetic properties of Sample $C$ is relatively higher than all other PNC samples. The findings from all characterisation is summarized in Table 3. As seen in Table 3, we have chosen Sample $C$ for self-healing application as it will interact strongly with external electromagnetic field, melt at lower temperature and provide highest tensile strength. Sample $E$ was not chosen despite of its higher magnetic properties than Sample $C$ to avoid localized pyrolysis due to the uneven dispersion and agglomeration concerns. During cooling-heating cycle during multiple self-healing, the interactions between molecules impart the capability of adhesion using directional interactions that dictate the mechanical properties of a material. (49). The longer aliphatic coating reduce the cluster stability and hence can result in increased self-healing efficiency $(49,50)$.

\subsection{Tensile strength of the composite GFRP samples.}

The tensile tests were conducted to determine the tensile strength of the multilayered GFRP- PNC composite sample (Figure 4). Tensile load was applied to multilayered GFRP-PNC composite dog bone, now referred as "virgin sample", to obtain relation of applied load to elongation (Figure 11 (a)). Obtained results show an initial linear deformation region, followed by a small non-linear plastic deformation and final failure. As seen in Figure 11 (a), the maximum load sustained by the virgin sample before final break-up was $150 \mathrm{~N}$. At maximum load, the crack on the sample started developing and brought about a loss of the storage modulus as a sudden drop in the load was witnessed (inset image shows the initial breakage, leading to the initiation of crack propagation and failure at the peak load). Adding extra layers did not increase the tensile strength of the virgin sample, and the maximum tensile stress was found to be comparable with that of the commercially available Vitcas (in as bought condition) glass fibres composite tape (51). The early stage crack initiation followed by the fibre failure was 
observed (Figure 11(b) black curve); this is the usual phenomenon observed in the failure of the glass fibre composites (52).

In comparison to virgin sample, the cracked virgin sample showed reduction of $24 \%$ in its elongation and $21 \%$ in its tensile strength, which is evident in Figure 11 (b) (red dashed curve as compared to the black curve). Corresponding maximum tensile load of cracked virgin sample was found to be $114.04 \mathrm{~N}$, dropped from the 150 $\mathrm{N}$ of virgin sample. After self-healing, the maximum tensile load of the sample was recovered but it was not as high as virgin sample's. Secondly, the failure of the healed sample was different than the one observed in virgin samples. Unlike virgin sample, the healed sampled failure was gradual and stepwise and the drop in tensile strength was prominent after each drop as it is manifested in blue curve of Figure 11 (b).

\section{EFFICIENCY OF SELF-HEALING OFFERED BY THE PROPOSED METHOD.}

The self-healing is effective in regaining the strength of the composite sample. The maximum tensile stress of the sample improved by approximately $10 \%$ after $1^{\text {st }}$ healing compared to tensile strength of the cracked virginsample. To compare the healing efficiency, the healing efficiency was defined as the ratio of the tensile strength of the healed sample to the original sample. The healing efficiency was measured using the tensile test results for the subsequent healing. The response after each healing was compared with that of the virgin sample to make a clear distinction and test the viability of such composite materials in rendering the best outcome. The efficiencies based on strength recovery were calculated as $84 \%, 58 \%$ and $34 \%$ after first, second and third healing, respectively. Though the subsequent efficiencies are less after the first healing attempt, it's not only because of the lack of healing capability but because the sample itself is damaged in a way that can't be completely recovered, as is seen in the inset images in Figure 11 (b). This enunciates that this method of self-healing has a capability of improving the overall life of the structure by $\approx 175 \%$, based on recovery efficiency. Until now there have been many concepts of self-healing for structural application, few of the relevant reported results with the lowest to highest efficiencies are summarised in Table 4.

Though these reported methods have shown satisfying results, our proposed methods showed ability to heal the crack irrespective of its location on the surface area of the component. As PNC film is beneath every millimeter of the composite tape, the defect on the surface of the composite can repaired by activating the flow of healing agent. It may not possible in other methods. The methods have certain limitations as listed in Table 4.

\section{CONCLUSIONS}

Notably, this is a first report of method capable of self-healing the large structure made using the fibre reinforced thermoplastic tape placement. Though many self-healing concepts for FRP composites have been proposed until now, but still their commercial application hasn't been tested yet (53). In this study, we have presented the concept of self-healing to enhance the life-cycle of thermoplastic fibre reinforced tape layered composite onshore and offshore structure through damage control. The concept is tested using a multilayer dog bone sample and is shown to recover $84 \%$ of original strength. The designed PNC was optimised for effective dispersion and physical properties which is suitable for the structural bonding of the GFRP composites. The concept of self-healing and its seamless integration method is presented in detail. The results showed healing efficiency to be $84 \%, 58 \%$, and 
$34 \%$ for first and subsequent healings. Furthermore, it has been demonstrated that the overall life of the structure can be achieved in region of $175 \%$ using this method.

Conflicts of Interest: The authors declare no conflict of interest.

\section{Acknowledgments:}

The authors thank Robert Gordon University for its financial support, in particular Ranjeetkumar's PhD funding. The authors are also grateful to the staff of School of Engineering (Alan Mclean, Alexander Laing, David Smith, Martin Johnstone, Alan Macpherson and the EA Team). Also, the staff of the School of Pharmacy at Robert Gordon University for making their facility available for part of this research, in particular we like to thank Laurie Smith, Bruce Petrie, Carlos Fernandez, Jenny Macaskill \& Tracy Willox. Support from the Science and Technology Facilities Council (STFC) for access to facilities at the ISIS Materials Characterisation Laboratory, STFC Rutherford Appleton Laboratory (RAL) was crucial for the research presented. 


\section{List of Figures:}

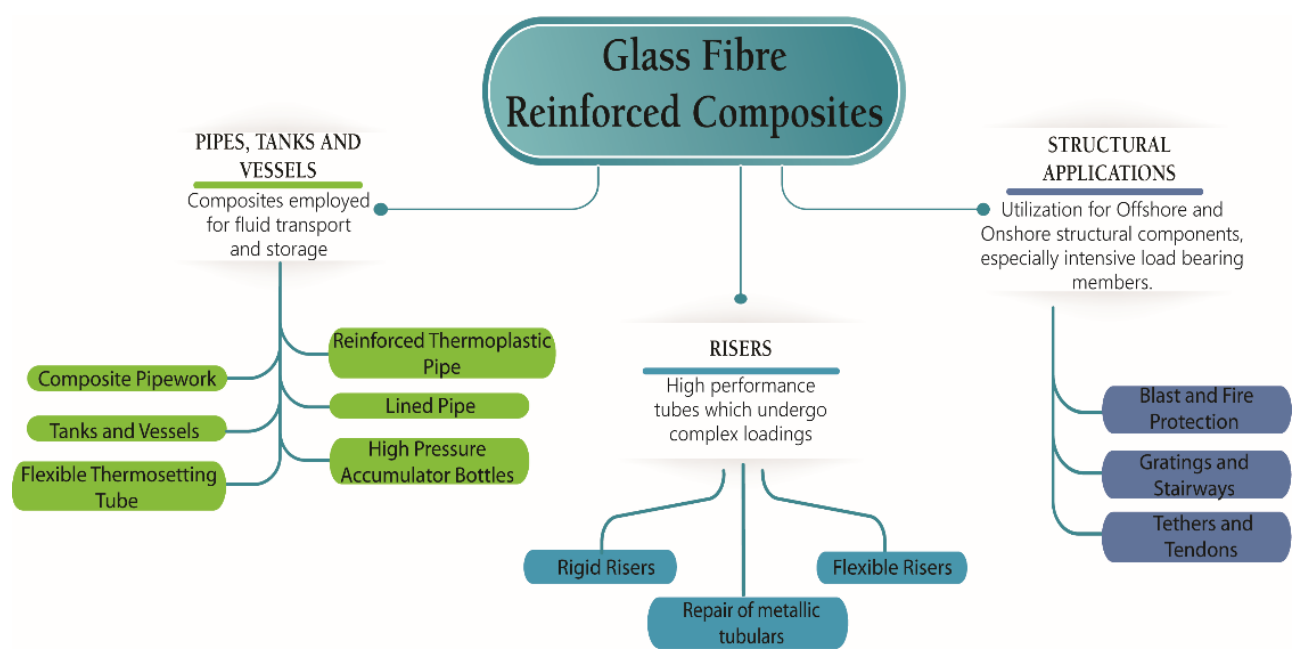

Figure 1. The onshore and offshore applications of GFRP composites
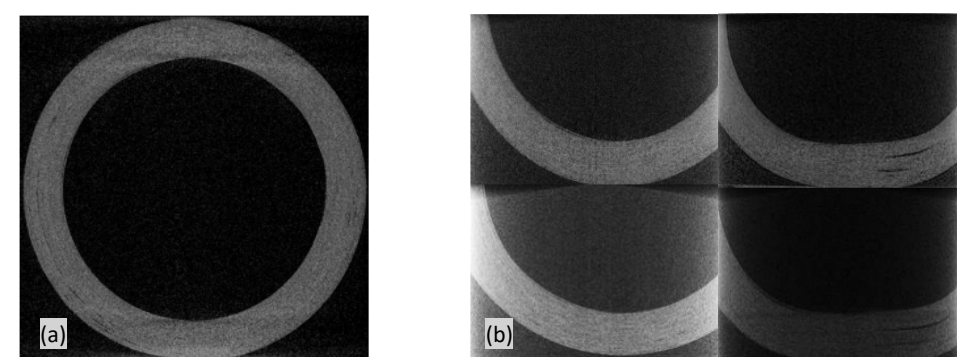

Figure 2. (a) An image showing cross-section of the composite pipe before compression testing. (b) The typical temporal lapsed images showing the composite ring section under compressive load at different time step (starts from bottom left in clockwise direction).

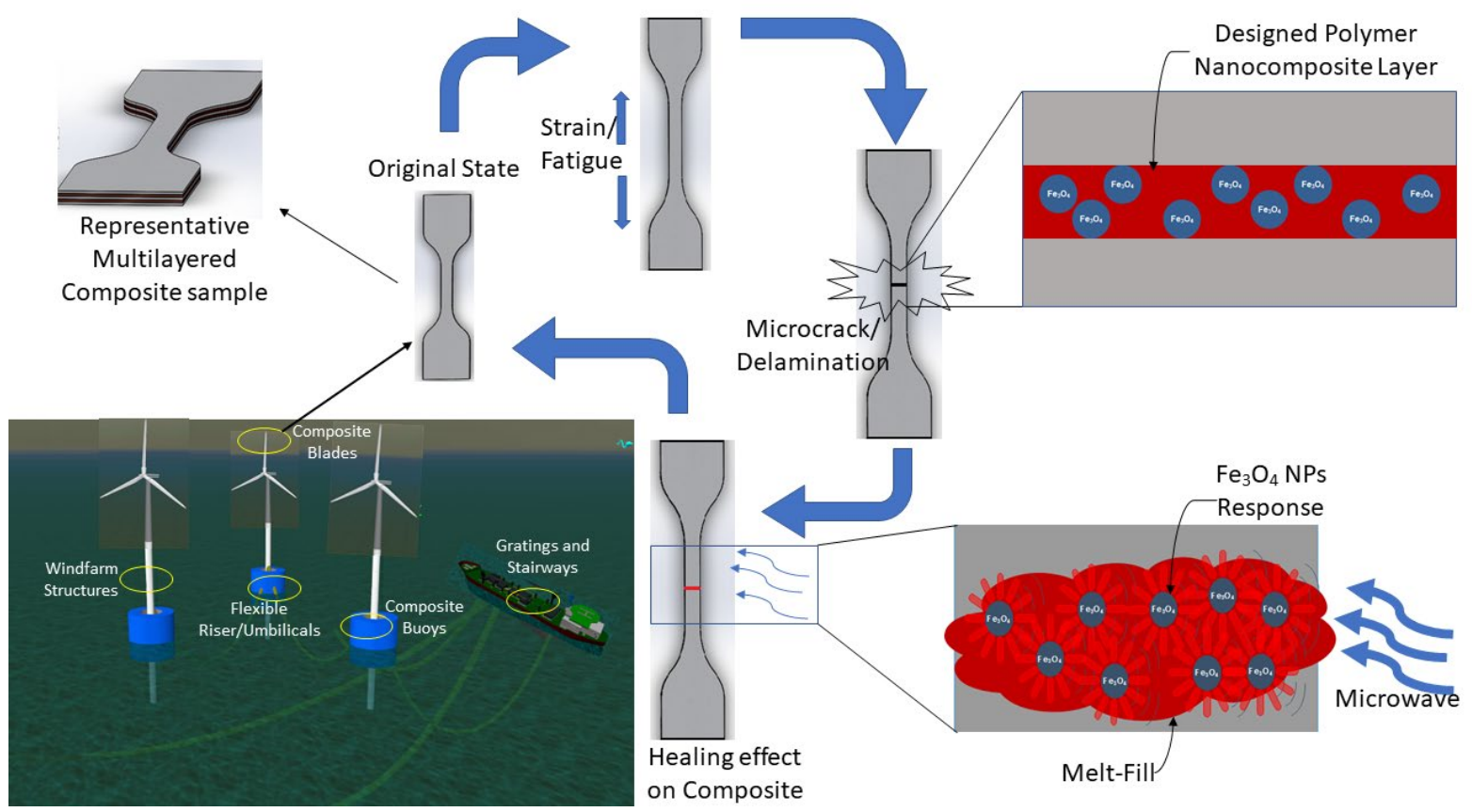

Figure 3. Proposed self-healing method 


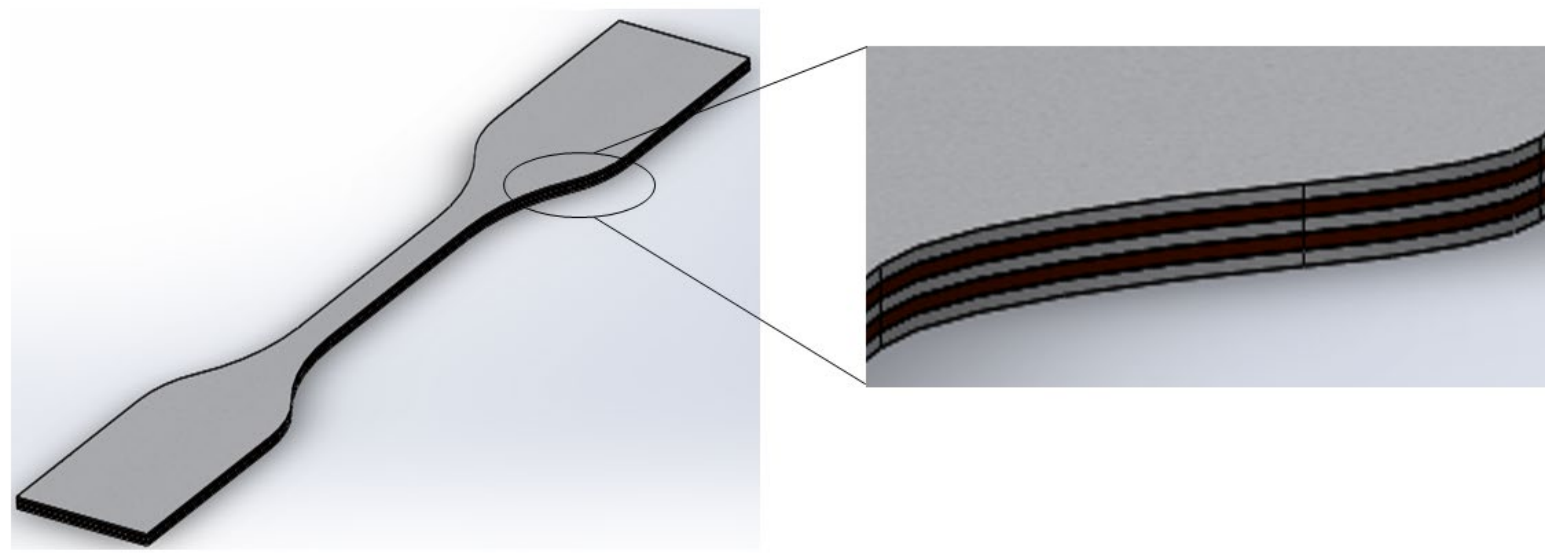

Figure 4. Standard dogbone samples prepared, showing different layers of the composite sample in CAD representation. (Inset image on right shows the arrangement of the layers in detail. The grey coloured layers represent the glass fibre tape whereas the black layers represent the PNC (nanocomposite) film.)

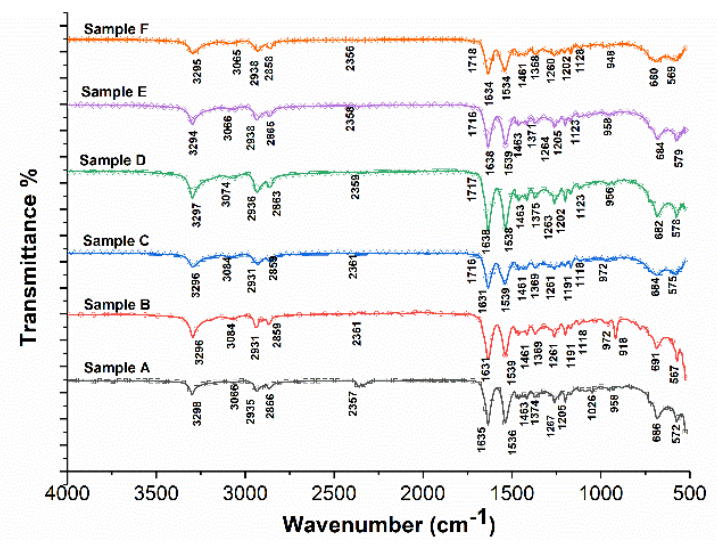

Figure 5. ATR-FTIR Spectra of polymer samples containing MNPs with varying proportions of OA coatings.

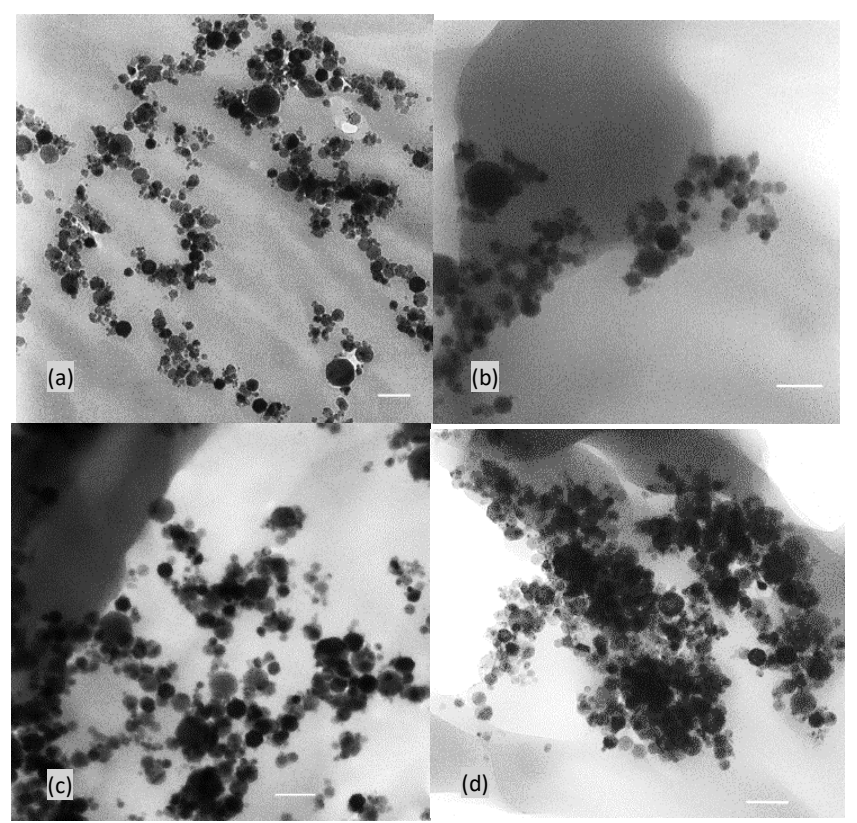

Figure 6. TEM images of microtome sections of (a) Sample C, (b) Sample D, (c) Sample E and (d) Sample F showing dispersion of nanoparticles in PA-6 matrix (scale $50 \mathrm{~nm}$ ) 


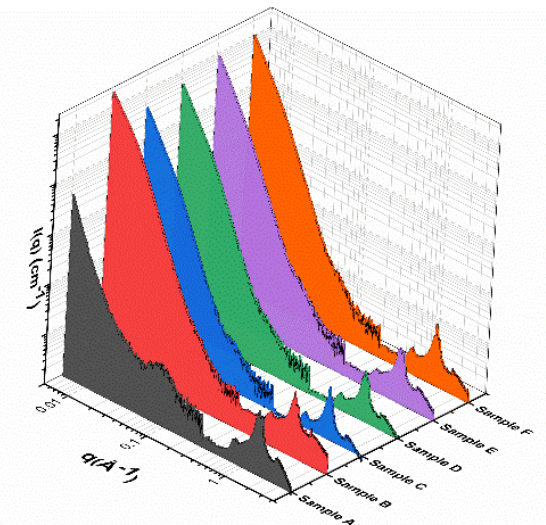

Figure 7. Background corrected SAXS $\left(0.005-0.3 \AA^{-1}\right)$ and WAXS $\left(0.3-4.17 \AA^{-1}\right)$ intensities I(q) as a function of the scattering vector ' $\mathrm{q}$ ' for all the samples studied.

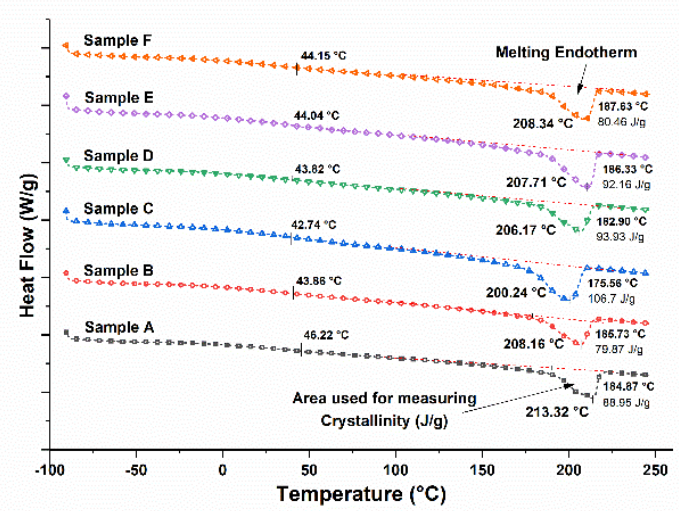

Figure 8. DSC curves of the PA6 samples containing MNPs with varying percentages of OA coating.

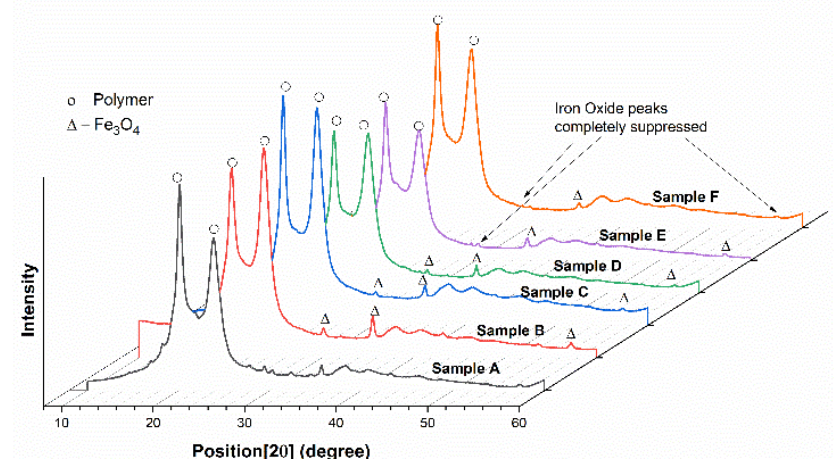

Figure 9. XRD patterns of the PA6 samples containing MNPs with varying percentages of OA coating. 
(a)

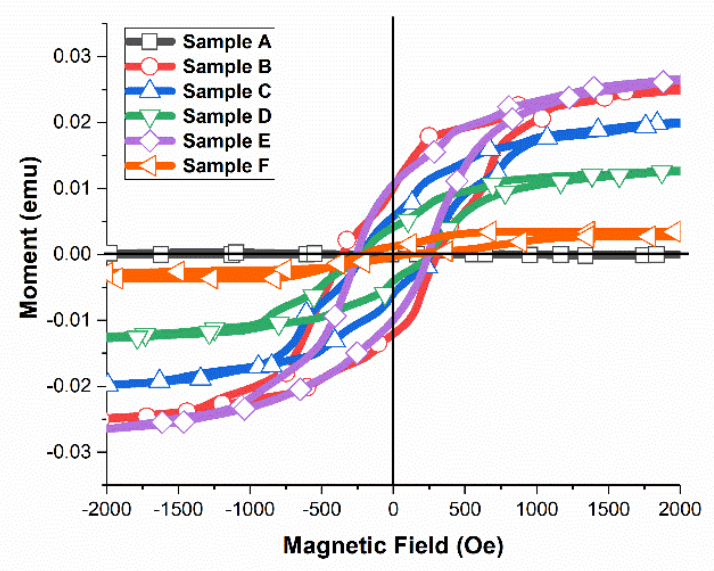

(b)

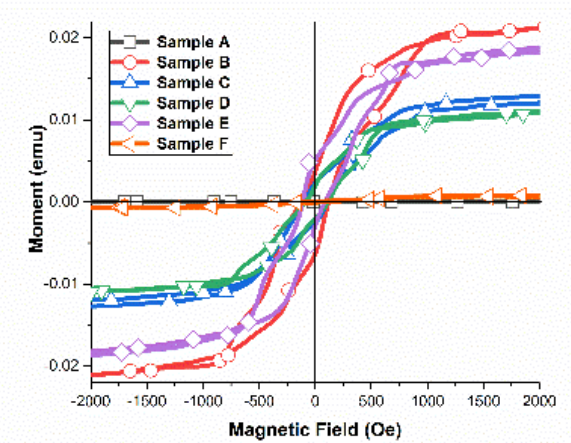

Figure 10. Magnetisation hysteresis loops for all samples at (a) $100 \mathrm{~K}$ and (b) $400 \mathrm{~K}$

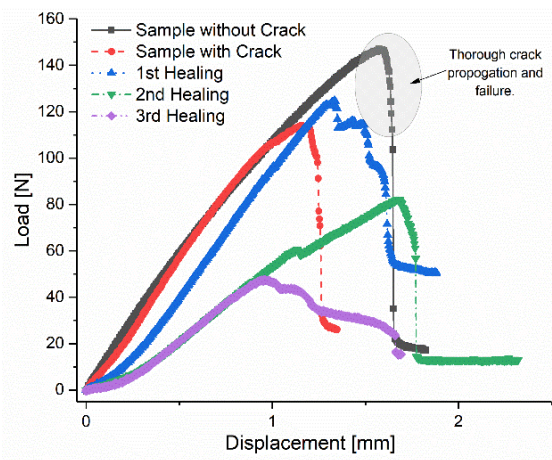

Figure 11 (a) Load-displacement curves measured during tensile testing of virgin sample without and with crack, and the subsequent healings. 


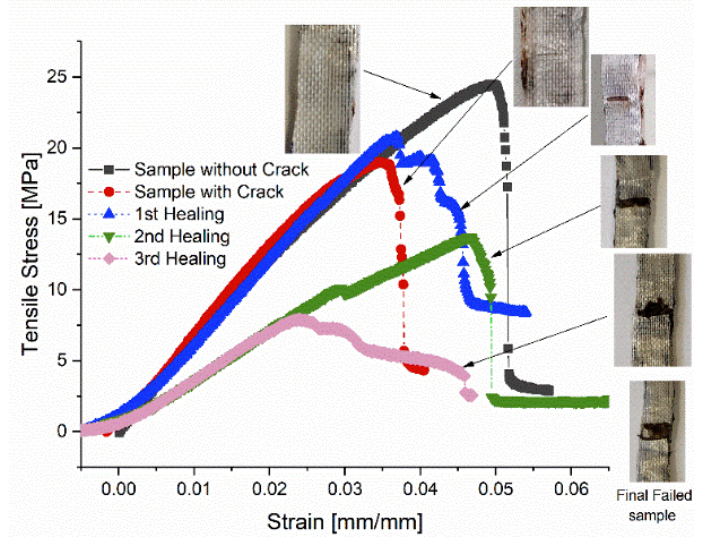

Figure 11 (b) Stress-Strain curves measured during tensile testing of virgin sample without and with crack, and the subsequent healings. 
Table 1

Details of prepared samples.

\begin{tabular}{ccccc}
\hline Sample Description & $\begin{array}{c}\text { OA loading of Iron } \\
\text { Oxide MNPs } \\
\text { coating }(\mathrm{w} / \mathrm{w} \%)\end{array}$ & $\begin{array}{c}\text { Iron Oxide MNPs } \\
\text { concentration }(\mathrm{w} / \mathrm{w} \\
\%)\end{array}$ & Polymer Matrix & $\begin{array}{c}\text { Referred in the } \\
\text { text as }\end{array}$ \\
\hline Pristine polymer & 0 & 0 & PA6 & Sample A \\
No coating & 0 & 1 & PA6 & Sample B \\
$22 \mathrm{w} / \mathrm{w} \%$ & 22 & 1 & PA6 & Sample C \\
$33 \mathrm{w} / \mathrm{w} \%$ & 33 & 1 & PA6 & Sample D \\
$44 \mathrm{w} / \mathrm{w} \%$ & 44 & 1 & PA6 & Sample E \\
$55 \mathrm{w} / \mathrm{w} \%$ & 55 & 1 & PA6 & Sample F \\
\hline
\end{tabular}

\section{Table 2}

The representative mean diameter of the MNP agglomerates present in the each PNC sample types. The SAXS data (I(q) and $\mathrm{Rg}$ ) plotted as Guinier plot were used to calculate the mean diameter, which describes the dispersion state of the MNPs in the polymer.

\begin{tabular}{|c|c|c|c|c|c|c|}
\hline & & Sample B & Sample C & Sample D & Sample E & Sample F \\
\hline \multirow{3}{*}{$\begin{array}{l}1^{\text {st }} \\
\text { Region } \\
\text { Fitting }\end{array}$} & $\begin{array}{c}I(q) \\
\text { Range }\end{array}$ & 0.009-0.012 & $0.009-0.014$ & $0.009-0.013$ & $0.009-0.012$ & 0.009-0.012 \\
\hline & $R_{g}$ & 196.719 & 151.196 & 166.46 & 196.86 & 185.136 \\
\hline & $D(n m)$ & 50.79 & 39.04 & 42.38 & 58.67 & 47.80 \\
\hline \multirow{3}{*}{$\begin{array}{l}2^{\text {nd }} \\
\text { Region } \\
\text { Fitting }\end{array}$} & $\begin{array}{c}I(q) \\
\text { Range }\end{array}$ & $0.012-0.018$ & $0.014-0.021$ & $0.013-0.021$ & $0.012-0.021$ & $0.012-0.019$ \\
\hline & $R_{g}$ & 143.985 & 94.057 & 116.67 & 145.28 & 121.676 \\
\hline & $D(n m)$ & 37.17 & 24.29 & 29.89 & 36.74 & 31.41 \\
\hline \multirow{3}{*}{$\begin{array}{l}3^{\text {rd }} \\
\text { Region } \\
\text { Fitting }\end{array}$} & $\begin{array}{c}I(q) \\
\text { Range }\end{array}$ & $0.018-0.022$ & - & - & - & - \\
\hline & $R_{g}$ & 97.123 & - & - & - & - \\
\hline & $D(n m)$ & 25.08 & - & - & - & - \\
\hline
\end{tabular}

The method of calculations and explanation on parameters such as $D$, Rg and I(q) are described in Supplementary Data, Section 3, S(3).

Table 3

Summary of key findings from all the characterisation results

\begin{tabular}{cccccl}
\hline Sample & $\mathrm{T}_{\mathrm{m}}\left({ }^{\circ} \mathrm{C}\right)$ & $\begin{array}{c}\text { Degree of } \\
\text { Crystallinity } \\
\text { (DSC Results) } \\
(\%)\end{array}$ & $\begin{array}{c}\text { Crystallite } \\
\text { size }(\mathrm{nm}) \\
\text { (XRD } \\
\text { Results) }\end{array}$ & $\begin{array}{c}\text { Magnetic } \\
\text { Saturation } \\
\text { (SQUID } \\
\text { Results) } \\
(\%)\end{array}$ & \multicolumn{1}{c}{ Findings } \\
\hline Sample B & $213.32 \pm 2$ & $46.81 \pm 2$ & $41.76 \pm 2$ & 65 & $\begin{array}{l}\text { High crystallite size \& melting } \\
\text { temperature, very low degree of } \\
\text { crystallinity and possibility of } \\
\text { pyrolysis. }\end{array}$ \\
Sample C & $200.24 \pm 3$ & $56.15 \pm 4$ & $30.02 \pm 3$ & 47 & $\begin{array}{l}\text { Lowest crystallite size \& melting } \\
\text { temperature, with highest degree of } \\
\text { crystallinity. Least possibility of } \\
\text { pyrolysis and maximum magnetic } \\
\text { response. }\end{array}$ \\
Sample D & $206.17 \pm 3$ & $49.44 \pm 6$ & $36.47 \pm 4$ & 30 & $\begin{array}{l}\text { Moderate crystallite size, melting } \\
\text { temperature and degree of }\end{array}$ \\
\hline
\end{tabular}




\begin{tabular}{ccccl} 
& & & & $\begin{array}{l}\text { crystallinity. Slight possibility of } \\
\text { pyrolysis and low magnetic } \\
\text { response. }\end{array}$ \\
& & & & $\begin{array}{l}\text { Highest crystallite size, melting } \\
\text { temperature and lower degree of } \\
\text { crystallinity. Highest pyrolysis and } \\
\text { magnetic response. }\end{array}$ \\
Sample E $207.71 \pm 2$ & $48.51 \pm 3$ & $47.65 \pm 11$ & 69 & $\begin{array}{l}\text { Low crystallite size \& degree of } \\
\text { crystallinity and high melting } \\
\text { temperature. Possibility of pyrolysis } \\
\text { and least magnetic response. }\end{array}$ \\
\hline
\end{tabular}

Table 4

Some concepts of self-healing composites proposed for structural applications.

\begin{tabular}{|c|c|c|c|c|}
\hline Techniques & $\begin{array}{l}\text { Matrix/Filler } \\
\text { Combination }\end{array}$ & $\begin{array}{l}\text { Reported } \\
\text { Efficiency }\end{array}$ & References & Limitations \\
\hline \multirow{4}{*}{ 1. Microencapsulation } & $\begin{array}{lll}\text { Epon } & 828 \text { with }\end{array}$ & $38 \% \& 66 \%$ & $(54)$ & \multirow{4}{*}{$\begin{array}{l}\text { Requires a definite volume of } \\
\text { catalyst loading; acts only on } \\
\text { successful rupture of the } \\
\text { microcapsule. }\end{array}$} \\
\hline & Carbon Fibre & $38 \% \propto 00 \%$ & (54) & \\
\hline & $\begin{array}{l}\text { Epon } 862 \text { with glass } \\
\text { fabric }\end{array}$ & $68 \% \& 78 \%$ & (13) & \\
\hline & $\begin{array}{l}\text { Epon } 862 \text { with E- } \\
\text { glass }\end{array}$ & $100 \%$ & $(55)$ & \\
\hline \multirow{5}{*}{$\begin{array}{l}\text { 2. Hollow Glass fibres } \\
\text { (HGF) }\end{array}$} & Epoxy with HGF & $5 \%$ & $(56)$ & \multirow{5}{*}{$\begin{array}{l}\text { An alternative to } \\
\text { microcapsules, but with } \\
\text { similar limitations }\end{array}$} \\
\hline & Epoxy with H-glass & $19.3 \%$ & (57) & \\
\hline & $\begin{array}{l}\text { Epon } 828 \text { with E- } \\
\text { glass }\end{array}$ & $62 \%$ & $(58)$ & \\
\hline & Epoxy with hexcel & $83.2 \%$ & $(59)$ & \\
\hline & Epoxy with HGF & $129 \%$ & $(60)$ & \\
\hline \multirow{3}{*}{ 3. Vascular } & Epoxy with E-glass & $40 \%$ & $(61)$ & \multirow{3}{*}{$\begin{array}{l}\text { Similar to hollow fibres, only } \\
\text { that it has a continue external } \\
\text { supply network of healing } \\
\text { agent, }\end{array}$} \\
\hline & Epoxy with E-glass & $67-74 \%$ & $(62)$ & \\
\hline & Epoxy with hexcel & $96-99 \%$ & $(63)$ & \\
\hline $\begin{array}{l}\text { 4. Reversible Covalent } \\
\text { bond }\end{array}$ & $\begin{array}{l}\text { Mendomer } \\
\text { carbon fibre }\end{array}$ & $92-94 \%$ & $(64)$ & $\begin{array}{l}\text { Reversible crosslinks are } \\
\text { activated upon heating, but } \\
\text { they are limited with low } \\
\text { temperature resistance }\end{array}$ \\
\hline $\begin{array}{l}\text { 5. Supramolecular } \\
\text { interactions }\end{array}$ & $\begin{array}{l}\text { Reverlink with E- } \\
\text { glass }\end{array}$ & $100 \%$ & $(53,65)$ & $\begin{array}{l}\text { Based on non-covalent } \\
\text { interactions, but result in } \\
\text { poor } \\
\text { performance }\end{array}$ \\
\hline 6. Polymer blends & $\begin{array}{l}\text { Epon } 828 \text { with E- } \\
\text { glass }\end{array}$ & $30 \%$ & $(17,66)$ & $\begin{array}{l}\text { Thermoplastic phase is } \\
\text { dispersed within a thermoset }\end{array}$ \\
\hline
\end{tabular}




\begin{tabular}{|c|c|c|c|}
\hline $\begin{array}{l}\text { Epon } 828 \text { with E- } \\
\text { glass }\end{array}$ & $94.9 \%$ & $(67,68)$ & $\begin{array}{l}\text { host to facilitate crack } \\
\text { healing, but the compatibility }\end{array}$ \\
\hline $\begin{array}{l}\text { Epoxy with carbon } \\
\text { fibre }\end{array}$ & $156 \%$ & $(69,70)$ & $\begin{array}{l}\text { of two is a major concern and } \\
\text { such healing is also induced } \\
\text { with gas pockets }\end{array}$ \\
\hline
\end{tabular}




\section{References}

1. Agarwal BD, Broutman LJ, Chandrashekhara K. Analysis and performance of fiber composites. In: John Wiley \& Sons; 2017. p. 1-16.

2. Chung DD. Composite materials: science and applications. In: Springer Science \& Business Media; 2010. p. 1-32.

3. Soutis C. Fibre reinforced composites in aircraft construction. Prog Aerospace Sci. 2005;41(2):143-51.

4. Zhong N, Post W. Self-repair of structural and functional composites with intrinsically selfhealing polymer matrices: A review. Composites Part A: Applied Science and Manufacturing. 2015;69:226-39.

5. Salski B, Gwarek W, Korpas P, Reszewicz S, Chong AY, Theodorakeas P, et al. Nondestructive testing of carbon-fibre-reinforced polymer materials with a radio-frequency inductive sensor. Composite Structures. 2015;122:104-12.

6. Pancholi K, Jha V, Dodds N, Huo D, Latto J. In situ and real time x-ray computed tomography for the micromechanics based constitutive modelling of the unbonded flexible riser. ASME 2015 34th international conference on ocean, offshore and arctic engineering; American Society of Mechanical Engineers; 2015.

7. Kashtalyan M, Soutis C. The effect of delaminations induced by transverse cracks and splits on stiffness properties of composite laminates. Composites Part A: Applied Science and Manufacturing. 2000;31(2):107-19.

8. Potluri P, Hogg P, Arshad M, Jetavat D, Jamshidi P. Influence of fibre architecture on impact damage tolerance in $3 \mathrm{D}$ woven composites. Applied Composite Materials. 2012;19(5):799-812.

9. Hu FZ, Soutis C. Strength prediction of patch-repaired CFRP laminates loaded in compression. Composites Sci Technol. 2000;60(7):1103-14.

10. Soutis C, Duan D, Goutas P. Compressive behaviour of CFRP laminates repaired with adhesively bonded external patches. Composite structures. 1999;45(4):289-301.

11. Caminero MA, Pavlopoulou S, Lopez-Pedrosa M, Nicolaisson B, Pinna C, Soutis C. Analysis of adhesively bonded repairs in composites: Damage detection and prognosis. Composite Structures. 2013;95:500-17.

12. Williams G, Bond I, Trask R. Compression after impact assessment of self-healing CFRP. Composites Part A: Applied Science and Manufacturing. 2009;40(9):1399-406.

13. Patel AJ, Sottos NR, Wetzel ED, White SR. Autonomic healing of low-velocity impact damage in fiber-reinforced composites. Composites Part A: Applied Science and Manufacturing. 2010;41(3):360-8.

14. Yin T, Rong MZ, Zhang MQ, Yang GC. Self-healing epoxy composites-preparation and effect of the healant consisting of microencapsulated epoxy and latent curing agent. Composites Sci Technol. 2007;67(2):201-12.

15. Yin T, Rong MZ, Wu J, Chen H, Zhang MQ. Healing of impact damage in woven glass fabric reinforced epoxy composites. Composites Part A: Applied Science and Manufacturing. 2008;39(9):1479-87.

16. Bond IP, Williams MGJ, Trask RS. Self-healing CFRP for aerospace applications. 16th. 2007.

17. Hayes S, Zhang W, Branthwaite M, Jones F. Self-healing of damage in fibre-reinforced polymer-matrix composites. Journal of the Royal Society Interface. 2007;4(13):381-7.

18. Banshiwal JK, Tripathi DN. Self-Healing Polymer Composites for Structural Application. In: Functional Materials. Intech Open; 2019. 
19. Gupta R, Pancholi K, Prabhu R, Pancholi M, Huo D, Jha V, et al. Integrated self-healing of the composite offshore structures. OCEANS 2017-aberdeen; IEEE; 2017.

20. Meure S, Furman S, Khor S. Poly [ethylene-co-(methacrylic acid)] healing agents for mendable carbon fiber laminates. Macromolecular Materials and Engineering. 2010;295(5):420-4.

21. Ahmed AS, Ramanujan RV. Curie temperature controlled self-healing magnet-polymer composites. J Mater Res. 2015;30(7):946-58.

22. Gupta R, Pancholi K, De S, Rulston, Murray D, Huo D, Droubi G, et al. Effect of Oleic Acid functionalised Iron Oxide Nanoparticles on Properties of Magnetic Polyamide-6 Nanocomposite The Journal of The Minerals, Metals \& Materials Society (TMS). 2019.

23. Fiabane J, Prentice P, Pancholi K. High yielding microbubble production method. BioMed Research International. 2016;2016.

24. Roth CB, Dutcher JR. Glass transition and chain mobility in thin polymer films. J Electroanal Chem. 2005;584(1):13-22.

25. Bronstein LM, Huang X, Retrum J, Schmucker A, Pink M, Stein BD, et al. Influence of iron oleate complex structure on iron oxide nanoparticle formation. Chemistry of materials. 2007;19(15):3624-32.

26. Kanchanomai C. Time-dependent fracture toughness of fumed silica/epoxy nanocomposites. J Composite Mater. 2012;46(16):1973-83.

27. Xu G, Lu W, Feng X, Yu S. Self-assembly of organic-inorganic nanocomposites with nacre-like hierarchical structures. Soft Matter. 2011;7(10):4828-32.

28. Ngwuluka N. Application of in situ polymerization for design and development of oral drug delivery systems. Aaps Pharm scitech. 2010;11(4):1603-11.

29. Pockett J. Crystallinity in linear polyamides: a study using melt blending with smallmolecule diluents [dissertation]. University of South Australia; 2004.

30. Yang F, Zhao M, Zheng B, Xiao D, Wu L, Guo Y. Influence of $\mathrm{pH}$ on the fluorescence properties of graphene quantum dots using ozonation pre-oxide hydrothermal synthesis. Journal of Materials Chemistry. 2012;22(48):25471-9.

31. Harrats C, Groeninckx G. Features, questions and future challenges in layered silicates clay nanocomposites with semicrystalline polymer matrices. Macromolecular Rapid Communications. 2008;29(1):14-26.

32. Tunc D, Bouchekif H, Améduri B, Jérôme C, Desbois P, Lecomte P, et al. Synthesis of aliphatic polyamide bearing fluorinated groups from $\varepsilon$-caprolactam and modified cyclic lysine. European Polymer Journal. 2015;71:575-84.

33. Shete P, Patil R, Tiwale B, Pawar S. Water dispersible oleic acid-coated Fe3O4 nanoparticles for biomedical applications. J Magn Magn Mater. 2015;377:406-10.

34. Doi M, Edwards SF. The theory of polymer dynamics. In: oxford university press; 1988. p. 140-76.

35. Teixeira J. Small-angle scattering by fractal systems. Journal of Applied Crystallography. 1988;21(6):781-5.

36. Porod G, Glatter O, Kratky O. Small angle X-ray scattering. by O.Glatter and O.Kratky, Academic Press, London. 1982:17.

37. Nylon-6 information and properties [Internet].; 2001 []. Available from: http://www.polymerprocessing.com/polymers/PA6.html.

38. Rittigstein P, Torkelson JM. Polymer-nanoparticle interfacial interactions in polymer nanocomposites: confinement effects on glass transition temperature and suppression of physical aging. Journal of Polymer Science Part B: Polymer Physics. 2006;44(20):2935-43.

39. Rybnikár F, Geil P. Melting and recrystallization of PA-6/PA-66 blends. J Appl Polym Sci. 1993;49(7):1175-88. 
40. Pashaei S, Avval MM, Syed AA. Thermal degradation kinetics of nylon6/GF/crysnano nanoclay nanocomposites by TGA. Chemical Industry and Chemical Engineering Quarterly/CICEQ. 2011;17(2):141-51.

41. Fornes T, Paul D. Crystallization behavior of nylon 6 nanocomposites. Polymer. 2003;44(14):3945-61.

42. Navarro-Pardo F, Martínez-Barrera G, Martínez-Hernández A, Castaño V, RiveraArmenta J, Medellín-Rodríguez F, et al. Effects on the thermo-mechanical and crystallinity properties of nylon 6, 6 electrospun fibres reinforced with one dimensional (1D) and two dimensional (2D) carbon. Materials. 2013;6(8):3494-513.

43. Voit W, Kim D, Zapka W, Muhammed M, Rao K. Magnetic behavior of coated superparamagnetic iron oxide nanoparticles in ferrofluids. MRS Online Proceedings Library Archive. 2001;676.

44. Sen T, Bruce IJ. Mesoporous silica-magnetite nanocomposites: fabrication, characterisation and applications in biosciences. Microporous and Mesoporous Materials. 2009;120(3):246-51.

45. Barrera G, Tiberto P, Allia P, Bonelli B, Esposito S, Marocco A, et al. Magnetic Properties of Nanocomposites. Applied Sciences. 2019;9(2):212.

46. Karna S, Mishra S, Gunapala E, Dubenko I, Malagareddy V, Marasinghe G, et al. Polymer assisted synthesis of FeNi nanoparticles. arXiv preprint arXiv:1212.3566. 2012.

47. Cho J, Paul D. Nylon 6 nanocomposites by melt compounding. Polymer. 2001;42(3):108394.

48. Jimenez G, Ogata N, Kawai H, Ogihara T. Structure and thermal/mechanical properties of poly (€-caprolactone)-clay blend. J Appl Polym Sci. 1997;64(11):2211-20.

49. Mphahlele K, Ray SS, Kolesnikov A. Self-healing polymeric composite material design, failure analysis and future outlook: a review. Polymers. 2017;9(10):535.

50. Guadagno L, Raimondo M, Naddeo C, Longo P, Mariconda A, Binder WH. Healing efficiency and dynamic mechanical properties of self-healing epoxy systems. Smart Mater Struct. 2014;23(4):045001.

51. Landesmann A, Seruti CA, Batista EdM. Mechanical Properties of Glass Fiber Reinforced Polymers Members for Structural Applications. Materials Research. 2015;18(6):1372-83.

52. Singh J, Kumar M, Kumar S, Mohapatra S. Properties of glass-fiber hybrid composites: a review. Polym Plast Technol Eng. 2017;56(5):455-69.

53. Cohades A, Branfoot C, Rae S, Bond I, Michaud V. Progress in self-healing fiberreinforced polymer composites. Advanced Materials Interfaces. 2018;5(17):1800177.

54. Kessler M, Sottos N, White S. Composites Part A: Appl. Sci.Manuf. 2003;34(8):743.

55. Moll JL, White SR, Sottos NR. A self-sealing fiber-reinforced composite. J Composite Mater. 2010;44(22):2573-85.

56. Bleay S, Loader C, Hawyes V, Humberstone L, Curtis P. A smart repair system for polymer matrix composites. Composites Part A: Applied Science and Manufacturing. 2001;32(12):1767-76.

57. Kling S, Czigány T. Damage detection and self-repair in hollow glass fiber fabricreinforced epoxy composites via fiber filling. Composites Sci Technol. 2014;99:82-8.

58. Zhu Y, Ye XJ, Rong MZ, Zhang MQ. Self-healing glass fiber/epoxy composites with polypropylene tubes containing self-pressurized epoxy and mercaptan healing agents. Composites Sci Technol. 2016;135:146-52.

59. Williams G, Trask R, Bond I. A self-healing carbon fibre reinforced polymer for aerospace applications. Composites Part A: Applied Science and Manufacturing. 2007;38(6):1525-32.

60. Trask R, Bond I. Biomimetic self-healing of advanced composite structures using hollow glass fibres. Smart Mater Struct. 2006;15(3):704. 
61. Williams H, Trask R, Bond I. Self-healing sandwich panels: restoration of compressive strength after impact. Composites Sci Technol. 2008;68(15-16):3171-7.

62. Luterbacher R, Trask R, Bond I. Static and fatigue tensile properties of cross-ply laminates containing vascules for self-healing applications. Smart Mater Struct. 2015;25(1):015003.

63. Norris CJ, Meadway GJ, O'Sullivan MJ, Bond IP, Trask RS. Self-healing fibre reinforced composites via a bioinspired vasculature. Advanced Functional Materials. 2011;21(19):362433.

64. Park JS, Kim HS, Hahn HT. Healing behavior of a matrix crack on a carbon fiber/mendomer composite. Composites Sci Technol. 2009;69(7-8):1082-7.

65. Sordo F, Michaud V. Processing and damage recovery of intrinsic self-healing glass fiber reinforced composites. Smart Mater Struct. 2016;25(8):084012.

66. Hayes S, Jones F, Marshiya K, Zhang W. A self-healing thermosetting composite material. Composites Part A: Applied Science and Manufacturing. 2007;38(4):1116-20.

67. Cohades A, Michaud V. Thermal mending in E-glass reinforced Poly $(\varepsilon-$ caprolactone)/epoxy blends. Composites Part A: Applied Science and Manufacturing. 2017;99:129-38.

68. Cohades A, Michaud V. Damage recovery after impact in E-glass reinforced poly ( $\varepsilon$ caprolactone)/epoxy blends. Composite Structures. 2017;180:439-47.

69. Pingkarawat K, Wang C, Varley RJ, Mouritz A. Effect of mendable polymer stitch density on the toughening and healing of delamination cracks in carbon-epoxy laminates. Composites Part A: Applied Science and Manufacturing. 2013;50:22-30.

70. Pingkarawat K, Bhat T, Craze D, Wang C, Varley RJ, Mouritz A. Healing of carbon fibreepoxy composites using thermoplastic additives. Polymer Chemistry. 2013;4(18):5007-15. 


\title{
Supplementary Data
}

\section{Novel Method of Healing the Fibre Reinforced Thermoplastic Composite: A Potential Model for Offshore Applications}

\author{
Ranjeetkumar Gupta ${ }^{1}$, Dehong Huo ${ }^{2}$, Maggie White ${ }^{3}$, Vineet Jha ${ }^{4}$, Gavin B. G. Stenning ${ }^{5}$, Ketan \\ Pancholi ${ }^{1 *}$ \\ ${ }^{1}$ School of Engineering, Robert Gordon University, Aberdeen AB10 7GE, UK \\ ${ }^{2}$ School of Engineering, Newcastle University, Newcastle upon Tyne, NE1 7RU, UK. \\ ${ }^{3}$ School of Chemical Engineering \& Advanced Materials, Newcastle University, NE1 7RU, UK. \\ ${ }^{4}$ GE Oil \& Gas, Newcastle upon Tyne, NE6 3PF, UK. \\ ${ }^{5}$ ISIS Neutron and Muon Facility, STFC Rutherford Appleton Laboratory, Didcot OX11 0QX, UK \\ *Correspondence: k.pancholi2@rgu.ac.uk; Tel.: +44-1224-262317.
}

Section 1 (S1) - Dimensions followed for preparation of standard dogbone sample (1).

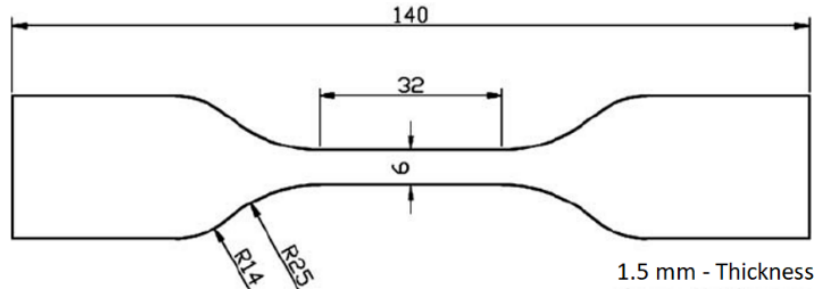

Fig. 1. Tensile testing specimen dimensions, with grip length $30 \mathrm{~mm}$ and the specimen width $25 \mathrm{~mm}$.

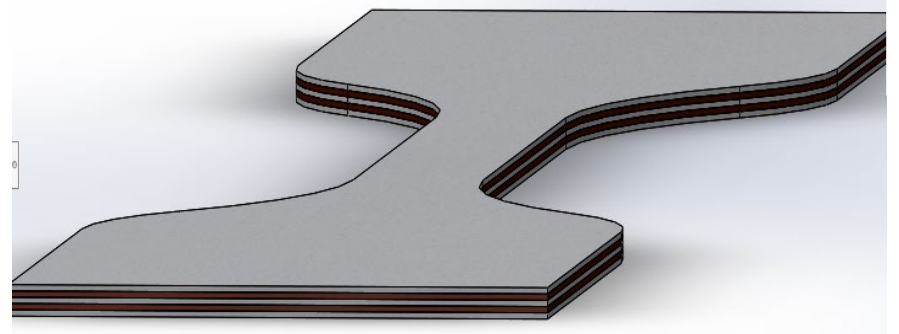

Fig. 2. Composite sample CAD representation

\section{Section 2 (S2) - Detailed MNP coating and PNC preparation method}

\section{Surface modification of iron oxide NPs with OA}

The $\mathrm{Fe}_{3} \mathrm{O}_{4}$ NPs were taken in four batches of $0.225 \mathrm{~g}$ each and dispersed in $10 \mathrm{ml}$ of methanol. Subsequently, the OA was added to individual batch to make up $22 \%, 33 \%, 44 \%$ and $55 \% \mathrm{w} / \mathrm{w}$ solution. Resulting solution was then mixed thoroughly using probe type sonicator (150 Watts for 10 minutes). After an hour, the mixture was centrifuged at $3500 \mathrm{rpm}$ for 8 minutes and the supernatant was discarded. In remaining NPs, the fresh methanol equivalent to discarded supernatant was added and cycle of ultrasonication and centrifugation was repeated three times to remove excess OA from the surface of iron oxide NPs. Each time the OA coated $\mathrm{Fe}_{3} \mathrm{O}_{4} \mathrm{NPs}_{\text {s were filtered }}$ using filter paper no. 1 and washed three times with deionized water. Finally, the particles were dried overnight in oven at $50^{\circ} \mathrm{C}$.

\section{Preparation of nanocomposite}

Prior to the polymerisation process, all MNPs used were exposed to UV radiation (36 Watts, $368 \mathrm{~nm}$ (peak wavelength)) for 30 minutes to remove any moisture. 
Separately, $30 \mathrm{~g}$ of CL was weighed in a beaker and heated to $90^{\circ} \mathrm{C}$ on a hot plate. Once monomer was fully melted in the beaker, the MNPs were added and resulting mixture was sonicated at $20 \mathrm{kHz}$ for 30 minutes to ensure uniform dispersion of the MNPs.

The mixture was then transferred to two necked flask and heated until $150^{\circ} \mathrm{C}$. The flask was continuously flushed with nitrogen to avoid moisture and its volatile reaction with catalyst EtMgBr. The EtMgBr measuring 1.2012 $\mathrm{mL}\left(2.5 \mathrm{~mole} \% \mathrm{~mol}^{-1} \mathrm{CL}\right)$ was extracted from the stock bottle using syringe while stock bottle was nitrogen flushed. Subsequently, EtMgBr was injected through rubber stopper fixed on two-necked flask. Next, $0.9415 \mathrm{~mL}$ $\left(2.5\right.$ mole \%) of NACL was introduced as an initiator to the mixture kept at $150^{\circ} \mathrm{C}$ (Optimised proportions of EtMgBr and NACL were used). As soon as NACL was introduced, the mixture was instantly polymerized. Once the nanocomposite was cool, then boiling water was used to wash recover nanocomposite from the glassware. The nanocomposite was then thoroughly washed before further characterization.

\section{Section 3 (S3) - Characterisation Methods in detail}

\section{FTIR-ATR}

The nanocomposite samples were characterized using Perkin-Elmer ATR-FTIR (Attenuated Total Reflection- Fourier Transmission Infrared Spectroscope) Spectrum Gx system containing DGS-KBr sensor to identify phases and structural changes after addition of the iron oxide NPs. In order to scan each sample, the nanocomposite films of approximately $0.1 \mathrm{~mm}$ thickness were prepared and total 30 scans in range of 525-4000 $\mathrm{cm}^{-1}$ wavelength were carried out at a resolution of $4 \mathrm{~cm}^{-1}$. The gain was set to "2" whereas the optical velocity was fixed to $0.4747 \mathrm{~m} / \mathrm{s}$.

\section{DSC}

DSC was performed using a TA Instruments DSC Q100 at a heating rate of $10^{\circ} \mathrm{C} / \mathrm{min}$ under a nitrogen environment with a temperature range of 20 to $270^{\circ} \mathrm{C}$ using a sample mass of $9 \mathrm{mg}$. The Heat/Cool/Heat standard cycle type analysis was selected for accurately depicting the behavior and $\mathrm{T}_{\mathrm{g}}$ and $\mathrm{T}_{\mathrm{m}}$ for the samples prepared. The running segment consisted of a ramp heating at $10{ }^{\circ} \mathrm{C} / \mathrm{min}$ to $250{ }^{\circ} \mathrm{C}$, then ramp cooling at $5{ }^{\circ} \mathrm{C} / \mathrm{min}$ to -90 ${ }^{\circ} \mathrm{C}$ and finally ramp heating at $10^{\circ} \mathrm{C} / \mathrm{min}$ to $250{ }^{\circ} \mathrm{C}$. The glass transition temperature $\left(\mathrm{T}_{\mathrm{g}}\right)$ and melting temperature $\left(\mathrm{T}_{\mathrm{m}}\right)$ were determined from the DSC traces obtained, where the first small endothermic peak represents the glass transition temperature and the second larger endothermic peak represents the melting temperature of the nanocomposite sample.

\section{XRD}

A PANalytical X'Pert Pro MPD, powered by a Philips PW3040/60 X-ray generator and fitted with an $\mathrm{X}^{\prime}$ Celerator detector was used. Diffraction data is acquired by exposing samples to $\mathrm{Cu}-\mathrm{K} \alpha \mathrm{X}$-ray radiation, which has a characteristic wavelength $(\lambda)$ of $1.5418 \AA$. X-rays were generated from a Cu anode supplied with $40 \mathrm{kV}$ and a current of $40 \mathrm{~mA}$. The data were collected over a range of 0 to $80^{\circ}(2 \theta)$ with a step size of $0.117 \mathrm{o}(2 \theta)$ and nominal time per step of 1099.82, using the scanning X'Celerator detector. Fixed anti-scatter and divergence slits of $0.38 \mathrm{~mm}$ were used together with a beam mask of $10 \mathrm{~mm}$ and all scans were carried out in a continuous' mode. Phase identification was carried out by means of the X'Pert-PRO accompanying software program PANalytical High Score Plus in conjunction with the JCPDS card.

\section{TEM}

TEM images were used to determine the morphology and mean diameter in the MNP agglomerates. TEM imaging was conducted at an accelerating voltage of $100 \mathrm{kV}$, with a spot size of $10 \mathrm{~nm}$. The exposure time was varied from 0 to $50 \mathrm{~s}$. The images of all samples were obtained using a Philips CM100 TEM at different direct magnifications, ranging from $\times 7900$ to $\times 245000$. An ultrathin section of nanocomposite obtained using microtome were placed on gilder grid of 400 mesh to obtain all images. For NPs imaging, the particles were dispersed in isopropyl alcohol and droplet were placed on TEM grid.

\section{SAXS/WAXS}

SAXS and WAXS scattering patterns were obtained on Xenocs Nano-inXider, equipped with microfocus sealed tube: $\mathrm{Cu}, 30 \mathrm{~W}=$, point focus. With Dectris Pilatus 3 hybrid photon counting (two fixed) detectors for continuous and simultaneous SAXS and WAXS acquisition up to $2 \theta=60^{\circ}$. The beam path was windowless beam path, entirely under vacuum from beam delivery system to detector sensor. The SAXS patterns were obtained over a scattering vector length within the range of $0.008 \AA^{-1}<\mathrm{q}<0.18 \AA^{-1}$ and WAXS patterns with the range of $0.18 \AA^{-1}<\mathrm{q}<0.24 \AA^{-1}$. One-dimensional (1D) fitting of the scattering curves were obtained by an azimuthal binning and averaging of corresponding two-dimensional scattering patterns using the XSACT (X-Ray Scattering Analysis and Calculation Tool) supplied with the instruments. 


\section{Magnetic characterisation}

Magnetization loops of the synthesised PNC samples were measured at $\mathrm{T}=100 \mathrm{~K}$ and $400 \mathrm{~K}$ on Quantum Design MPMS XL-7, integrated with Superconducting Quantum Interference Device (SQUID) detection system and precision temperature control unit. The instrument had temperature range of 1.8 to $400 \mathrm{~K}$ and applied maximum field strength of \pm 7 Tesla with filed uniformity of $0.01 \%$ over $4 \mathrm{~cm}$.

\section{SAXS/WAXS data analysis method}

All obtained spectra were corrected for background scattering before any further analysis.

$$
I(q)=G \exp \left(-\frac{q^{2} R_{g}^{2}}{3}\right) \quad \text { Eqn. } 1
$$

herein, $\mathrm{G}$ is the Guinier prefactor and $\mathrm{R}_{\mathrm{g}}$ the radius of gyration. The Guinier plot represented in Figure 3 of Supplementary Data S5, of $\operatorname{Ln} \mathrm{I}(\mathrm{q}) \mathrm{vs}^{2}$, is used to calculate the slope of the chosen region that dictates the value of $\mathrm{R}_{\mathrm{g}}$, giving out the $\mathrm{NP} /$ agglomerate size qualitatively.

The NPs are assumed as perfect sphere and the diameter D is calculated with the Equation 2 (2):

$$
D=2 \times(5 / 3)^{1 / 2} R_{g} \quad \text { Eqn. } 2
$$

The slope of regions in the Guinier plot were calculated to give the $\mathrm{R}_{\mathrm{g}}$ estimate (3), this was used to calculate the diameters of the NP/agglomerate using Equation 2.

\section{Section 4 (S4) - Detailed list of matching FTIR peaks.}

\begin{tabular}{lc}
\hline \multicolumn{1}{c}{ FTIR Assignment } & Peak Positions $\left(\mathrm{cm}^{-1}\right)$ \\
\hline Hydrogen Bonded N-H Stretch & $3296(3294-3298)$ \\
$\mathrm{CH}_{2}$ Asymmetric stretch & $2935(2931-2938)$ \\
$\mathrm{CH}_{2}$ Symmetric stretch & $2861(2858-2866)$ \\
Amide I and II, C-N stretch, N-H stretch, C(O)- & $1540(1534-1539)$ \\
N-H bend & $1700(1716-1718)$ \\
OA induced -COOH stretch & \\
\hline
\end{tabular}

Section 5 (S5) - SAXS Data fitting plots

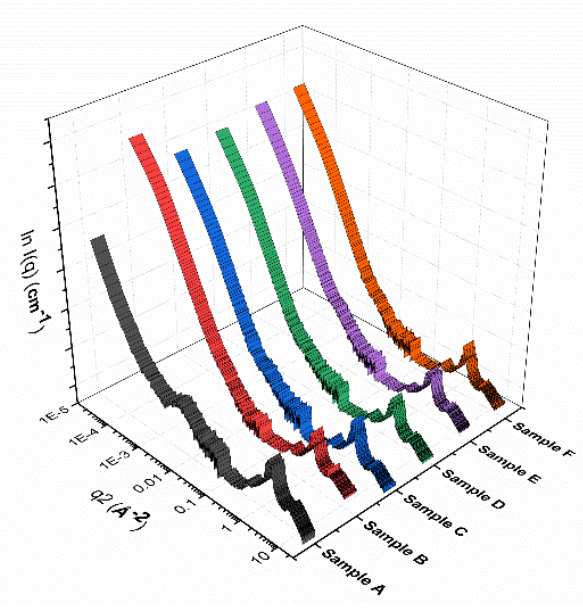




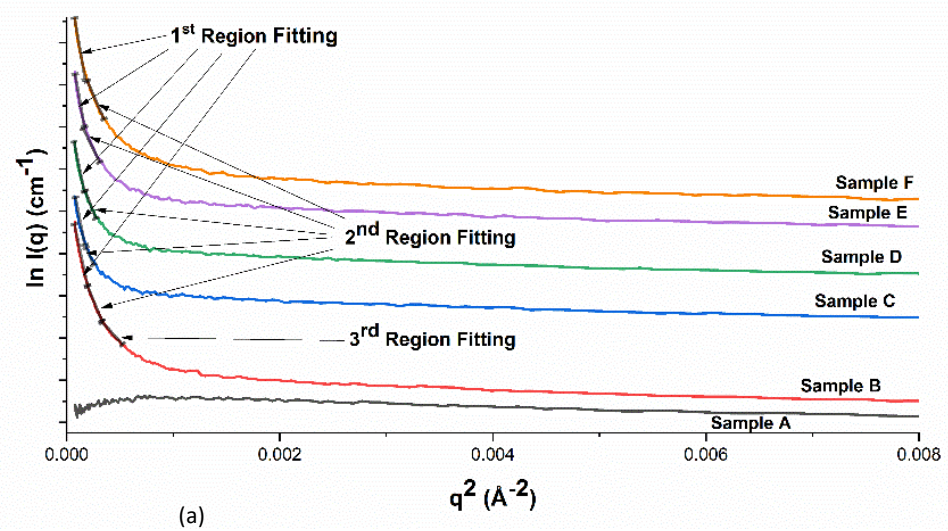

Fig. 3. (a) Guinier plot for all the samples and (b) the plot with the region of fitting highlighted.

\section{Section 6 (S6)}

The enthalpy of fusion for all the samples were calculated using the Universal Analysis software provided with the DSC Q100 instrument control package. The enthalpy of fusion (heats) of melting and enthalpy of cold crystallization were then determined by integrating the areas under the endotherm peaks. Using Equation 3, the degree of crystallinity was calculated, where PA 6 enthalpy represents the enthalpy (heat) of fusion for the $100 \%$ crystalline PA6 polymer. The areas used for the enthalpy (crystallinity) calculations were identified using the "Integrate Peak" functionality of the TA Universal Analysis 2000 software (4) and is clearly marked in the Fig. 8 of the main manuscript text. The intersection of the tangent to the melting peak along with same analysis helped identify the "Melt Peak Temperature" of the endotherm peak, which is referred as the melting point $\left(T_{m}\right)$ of the samples and listed in the Table below. Furthermore, the Glass transition temperature $\mathrm{T}_{\mathrm{g}}$ was also identified using the "Glass/Step transition" functionality available in the same software.

The degree of crystallinity for all the samples was calculated from the following Equation 3 (4), using the standard reference value of PA6 as cited in the main text.

$$
\text { Sample Degree of Crystallinity }=\frac{\text { Sample Enthalpy from DSC plot }}{\text { PA6 Enthalpy }} \times 100 \% \quad \text { Eqn. } 3
$$

Table: A list of degree of crystallinity, Glass transition $\left(T_{g}\right)$ and Melting temperature $\left(T_{m}\right)$ from DSC results.

\begin{tabular}{cccrc}
\hline Sample & $\mathrm{T}_{\mathrm{g}}\left({ }^{\circ} \mathrm{C}\right)$ & \multicolumn{1}{c}{$\mathrm{T}_{\mathrm{m}}\left({ }^{\circ} \mathrm{C}\right)$} & Enthalpy $(\mathrm{J} / \mathrm{g})$ & $\begin{array}{c}\text { Degree of Crystallinity } \\
(\%)\end{array}$ \\
\hline Sample $B$ & $46.22 \pm 1$ & $213.32 \pm 2$ & $88.95 \pm 2$ & $46.81 \pm 2$ \\
Sample $C$ & $42.74 \pm 2$ & $200.24 \pm 3$ & $106.7 \pm 4$ & $56.15 \pm 4$ \\
Sample D & $43.82 \pm 2$ & $206.17 \pm 3$ & $93.93 \pm 6$ & $49.44 \pm 6$ \\
Sample $E$ & $44.04 \pm 1$ & $207.71 \pm 2$ & $92.16 \pm 3$ & $48.51 \pm 3$ \\
Sample $F$ & $44.15 \pm 1$ & $208.34 \pm 2$ & $80.46 \pm 2$ & $42.34 \pm 2$ \\
\hline
\end{tabular}

\section{Section 7 (S7)}

The crystallite sizes of MNPs were calculated from FWHM of the most intense peaks present in the XRD plot. The Scherrer formula (5) as shown in Equation 4 was used to calculate the crystallite size. The Scherrer equation relates the peak width(B) and the crystallite size(L). It states that the peak width is inversely proportional to crystallite size.

$$
B(2 \theta)=\frac{K \lambda}{L \cos \theta}
$$

Eqn. 4

Where, $\mathrm{K}, \lambda$ and $\theta$ are Scherrer constant, X-ray wavelength and Bragg angle, respectively.

Table: Crystallite sizes of MNPs calculated from FWHM of intense peaks observed in XRD. 


\begin{tabular}{ccc}
\hline \multirow{2}{*}{ Sample Type } & \multicolumn{2}{c}{ Absolute Crystallite Size } \\
\cline { 2 - 3 } & Size $(\mathrm{A})$ & Size $(\mathrm{nm})$ \\
Sample B & 417.57 & 41.76 \\
Sample C & 300.21 & 30.02 \\
Sample D & 364.68 & 36.47 \\
Sample E & 476.47 & 47.65 \\
Sample F & 324.12 & 32.41 \\
\hline
\end{tabular}

Ideally, PA6 contains two dominant monoclinic crystalline phases that are usually referred to as the $\alpha$-phase and $\gamma$-phase. In the $\alpha$-phase, which is known to be the most stable phase in terms of thermodynamics, the hydrogen bonds appear in between adjacent antiparallel chains, with the entirety of the phase attaining a trans-chain conformity (6). This, however, is not the case in the $\gamma$-phase, as chains are seen to appear twisted in order to enable the formation of hydrogen bonds between parallel chains (6). Two broad peaks were seen to appear around 4.2 $\mathrm{A}^{\circ}\left(21^{\circ} 2 \theta\right)$ and $3.7 \mathrm{~A}^{\circ}\left(24^{\circ} 2 \theta\right)$ corresponds to $\alpha$-crystalline phase form in PA6. The $\alpha$ crystalline phase dominated the crystalline structure of prepared PA6. The line at $4.2 \mathrm{~A}^{\circ}$ referred to $\alpha 1$ and originated from (200) plane whereas $3.7 \mathrm{~A}^{\circ}$ originated from (002) plane (7). The peaks observed at $11^{\circ}, 22^{\circ}$ and $23^{\circ}$ can be identified as the $\gamma$-phase of the of PA6 with the corresponding indexes of (020), (001) and (200)/(201) (8).

The number of unit cells $(\mathrm{N})$ along their respective directions, define the broadening of the diffraction peaks. Though independent of the $\mathrm{N}$, the peak area remains constant. Therefore, the peak broadening in XRD results was accompanied by decrease in the maximum peak height. However, as seen in Fig. 9 (main manuscript) the peaks were broadened, and intensity was decreased when OA content in NP coating was increased to $22 \%$ (Sample C). After increasing OA loading in the coating, the crystallite size have started increasing up to Sample E.

There were many factors contributing to the observed peak profile. In essence, the peak profile shown in Fig. 9 in main manuscript was a deconvolution of the peak from other contributions such as instrumental peak profile, crystallite size, microstrain, solid solution inhomogeneity, and temperature factors

\section{Section 8 (S8)}

Full scale plots of induced magnetisation i.e. magnetic moment as a function of applied magnetic field, showing the associated hysteresis loops in inset figures at (a) $100 \mathrm{~K}$ and (b) $400 \mathrm{~K}$ temperatures.

(a)

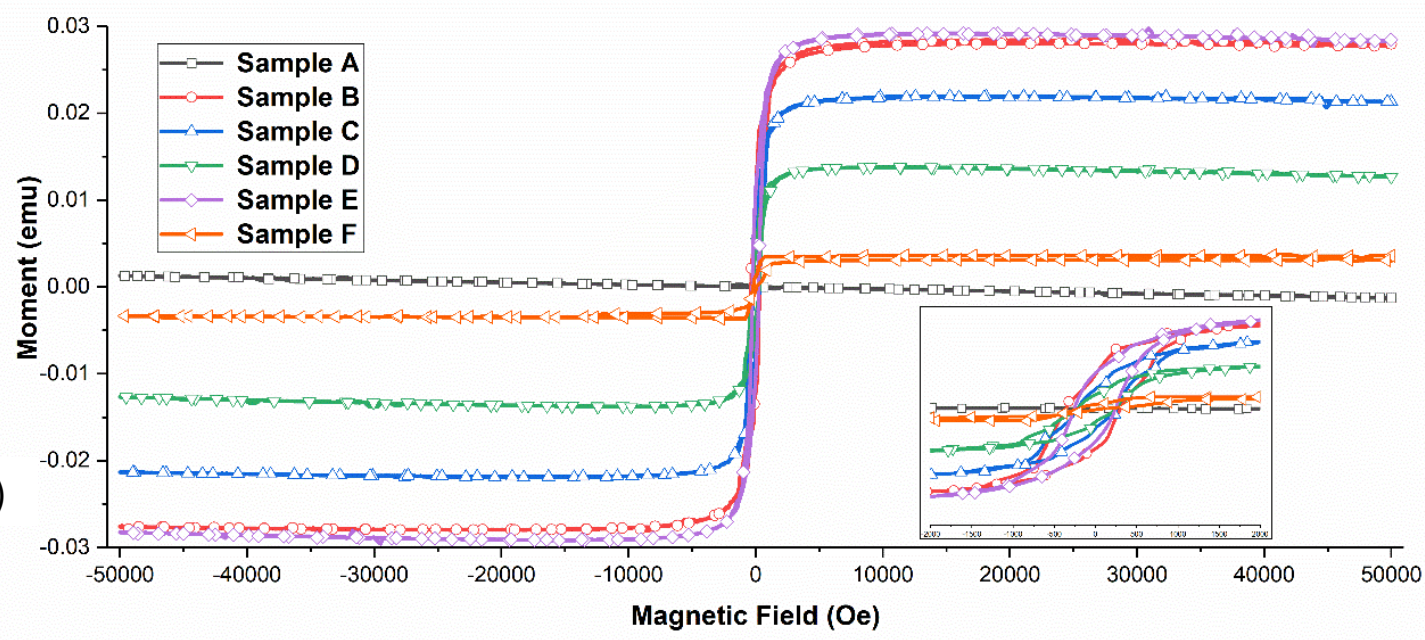




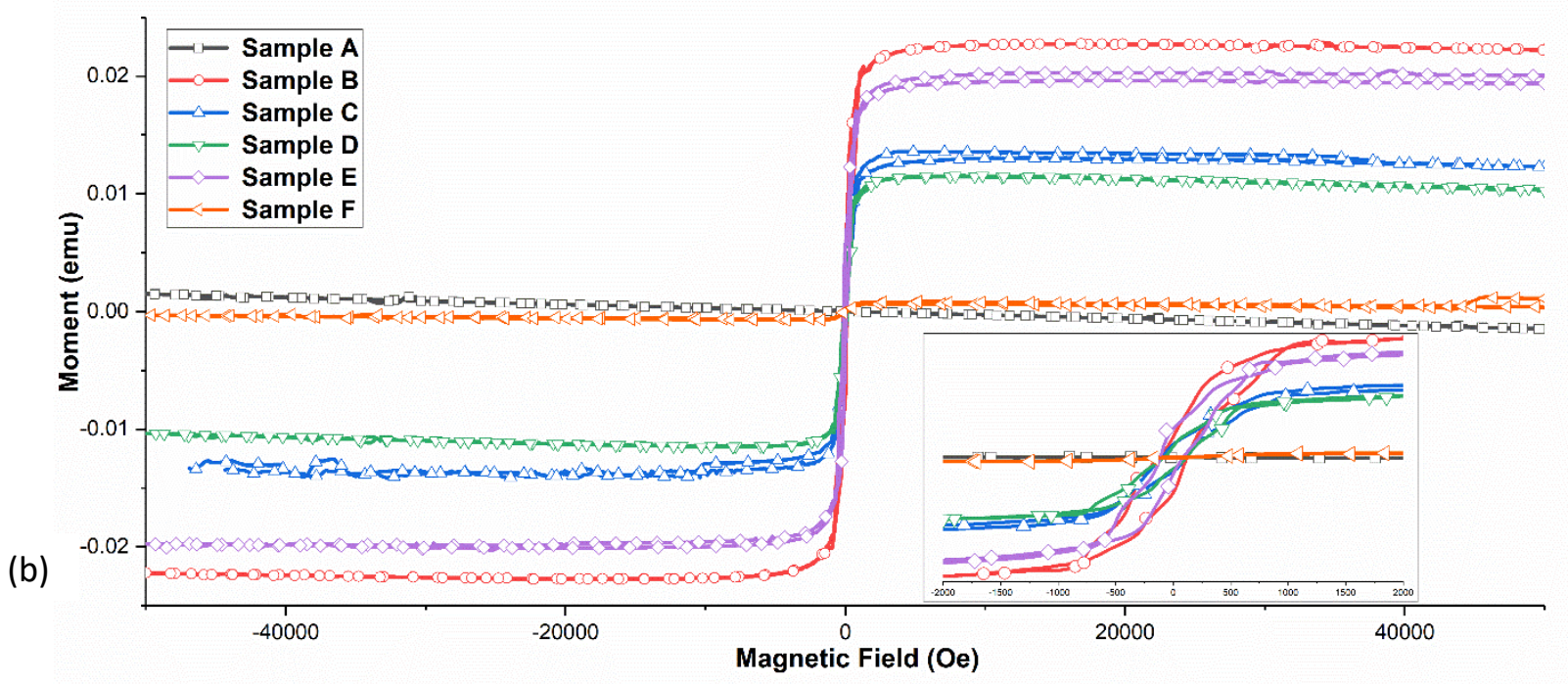

Fig. 4. Full scale plots of induced magnetisation (Magnetic moment as a function of applied magnetic field) and the associated hysteresis loops in inset figures at (a) $100 \mathrm{~K}$ and (b) $400 \mathrm{~K}$ temperatures.

\section{References}

1. Kanchanomai C. Time-dependent fracture toughness of fumed silica/epoxy nanocomposites. Journal of Composite Materials. 2012 Aug;46(16):1973-83.

2. Hino K, Shingai R, Morita T, Toku K, Hirano T, Yoshikawa H, et al. Size distribution of gold nanoparticles covered with thiol-terminated cyanobiphenyl-type liquid crystal molecules studied with small-angle X-ray scattering and TEM. Chemical Physics Letters. 2008;460(1-3):173-7.

3. Piiadov V, Ares de Araújo E, Oliveira Neto M, Craievich AF, Polikarpov I. SAXSMoW 2.0: Online calculator of the molecular weight of proteins in dilute solution from experimental SAXS data measured on a relative scale. Protein Science. 2019;28(2):454-63.

4. Blaine RL. Determination of polymer crystallinity by DSC. TA Instruments, New Castle, DE. 2013.

5. Speakman SA. Estimating crystallite size using XRD. MIT Center for Materials Science and Engineering. 2014:03-8.

6. Porter R. Macromolecular physics, volume 3-crystal melting, Bernhard Wunderlich. . 1980:363.

7. Shete P, Patil R, Tiwale B, Pawar S. Water dispersible oleic acid-coated Fe $3 \mathrm{O} 4$ nanoparticles for biomedical applications. J Magn Magn Mater. 2015;377:406-10.

8. Khodabakhshi K. Anionic polymarisation of caprolactam: an approach to optimising the polymerisation condition to be used in the jetting process [dissertation]. Loughborough University; 2011. 